\title{
Multi-Target Effects of the Cannabinoid CP55940 on Familial Alzheimer's Disease PSEN1 E280A Cholinergic-Like Neurons: Role of $\mathrm{CB}_{1}$ Receptor
}

\author{
Viviana Soto-Mercado, Miguel Mendivil-Perez, Marlene Jimenez-Del-Rio* and Carlos Velez-Pardo* \\ Neuroscience Research Group, Medical Research Institute, Faculty of Medicine, University of Antioquia (UdeA), \\ SIU Medellin, Colombia
}

Accepted 12 October 2020

Pre-press 23 November 2020

\begin{abstract}
.
Background: Alzheimer's disease (AD) is characterized by structural damage, death, and functional disruption of cholinergic neurons $(\mathrm{ChNs})$ as a result of intracellular amyloid- $\beta(\mathrm{A} \beta)$ aggregation, extracellular neuritic plaques, and hyperphosphorylation of protein tau (p-Tau) overtime.

Objective: To evaluate the effect of the synthetic cannabinoid CP55940 (CP) on PSEN1 E280A cholinergic-like nerve cells (PSEN1 ChLNs) - a natural model of familial AD.

Methods: Wild type (WT) and PSEN1 ChLNs were exposed to CP $(1 \mu \mathrm{M})$ only or in the presence of the $\mathrm{CB}_{1}$ and $\mathrm{CB}_{2}$ receptors $\left(\mathrm{CB}_{1} \mathrm{Rs}, \mathrm{CB}_{2} \mathrm{Rs}\right)$ inverse agonist SR141716 $(1 \mu \mathrm{M})$ and SR144528 $(1 \mu \mathrm{M})$ respectively, for $24 \mathrm{~h}$. Untreated or treated neurons were assessed for biochemical and functional analysis.

Results: $\mathrm{CP}$ in the presence of both inverse agonists (hereafter SR) almost completely inhibits the aggregation of intracellular sA $\beta P P \beta$ f and $\mathrm{p}$-Tau, increases $\Delta \Psi_{\mathrm{m}}$, decreases oxidation of DJ-1Cys ${ }^{106}$-SH residue, and blocks the activation of c-Jun, p53, PUMA, and caspase-3 independently of $\mathrm{CB}_{1}$ Rs signaling in mutant ChLNs. CP also inhibits the generation of reactive oxygen species partially dependent on $\mathrm{CB}_{1}$ Rs. Although $\mathrm{CP}$ reduced extracellular $\mathrm{A} \beta_{42}$, it was unable to reverse the $\mathrm{Ca}^{2+}$ influx dysregulation as a response to acetylcholine stimuli in mutant ChLNs. Exposure to anti-A $\beta$ antibody 6E10 (1:300) in the absence or presence of SR plus $\mathrm{CP}$ completely recovered transient $\left[\mathrm{Ca}^{2+}\right]_{\mathrm{i}}$ signal as a response to acetylcholine in mutant ChLNs.

Conclusion: Taken together our findings suggest that the combination of cannabinoids, $\mathrm{CB}_{1}$ Rs inverse agonists, and anti- $\mathrm{A} \beta$ antibodies might be a promising therapeutic approach for the treatment of familial AD.
\end{abstract}

Keywords: Apoptosis, cannabinoids, cholinergic neurons, CP55940, E280A mutation, familial Alzheimer disease, neuronal dysfunction, oxidative stress, PSEN1, sA $\beta P P \beta f$, tau

\footnotetext{
${ }^{*}$ Correspondence to: Carlos Velez-Pardo and Marlene JimenezDel-Rio, Neuroscience Research Group, Medical Research Institute, Faculty of Medicine, University of Antioquia (UdeA), Calle 70 No. 52-21, and Calle 62 \# 52-59, Building 1, Room 412; SIU Medellin, Colombia. E-mail: calberto.velez@udea.edu. co., ORCID \#0000-0002-0557-0411 (Velez-Pardo); E-mail: marlene.jimenez@udea.edu.co., ORCID \#0000-0003-3477-2386 (Jimenez-Del-Rio)
}

\section{INTRODUCTION}

Alzheimer's disease (AD) is a multifactorial neurodegenerative condition [1] characterized by severe loss of cholinergic neurons from the nucleus basalis magnocellularis of Meynert and cholinergic projections to the cortex and hippocampus [2]. The neuronal destruction is associated with the extracellular accumulation of insoluble forms of amyloid- $\beta$ $(A \beta)$ in plaques, mostly fragment $A \beta_{1-42}$ (hereafter 
$A \beta_{42}$ ), intracellular aggregation of the microtubule protein tau in neurofibrillary tangles, neuronal cell death, and synaptic dysfunction [3]. The $A \beta_{42}$ peptide is derived from the amyloid- $\beta$ protein precursor $(\mathrm{A} \beta \mathrm{PP})$ via sequential cleavage by the beta-site amyloid precursor protein cleaving enzyme 1 (BACE1) and by the gamma-site aspartyl protease $\gamma$-secretase [4]. This last protein is composed of four subunits, namely presenilins (PSEN1 and PSEN2), presenilin enhancer 2 (PEN2), anterior pharynx-defective 1 (APH-1), and nicastrin. While PEN2, APH-1, and nicastrin stabilize the complex, PSEN1 and PSEN2 function as the catalytic core of the protease [5]. Over two hundred autosomal dominant mutations in the presenilin 1 (PSEN 1) gene result in the overproduction of extracellular (e) $\mathrm{A}_{42}$ [6] and occur most frequently in familial AD (FAD; https://www.alzforum.org/mutations/ psen-1). Among PSEN1 mutations, the Glu280Ala (p. E280A, c.839A $>$ C, exon 8) in PSEN1 causes FAD with complete penetrance in a large kindred localized in Antioquia, Colombia [7-10]. As the majority of dominant-negative PSEN1 mutations [11], PSEN1 E280A produces increased $A \beta_{42}$ deposition [12], hippocampal neuron loss [13], and $A \beta /$ tau accumulation in young adults [14, 15]. Recently, we have recapitulated the molecular pathogenesis of FAD caused by PSEN1 E280A in umbilical cord mesenchymal stem cells-derived cholinergiclike neurons (ChLNs [16]). It has demonstrated that PSEN1 E280A ChLNs effectively exhibited not only an increased $\mathrm{eA} \beta_{42}$ but also an early increased of intracellular $\mathrm{sA} \beta \mathrm{PP} \beta$ fragments (but not $A \beta_{42}$ peptide) and tau phosphorylation. Moreover, PSEN1 E280A ChLNs exhibited oxidized DJ-1 (at $\mathrm{Cys}^{106} \mathrm{SO}_{3}$ ) indicative of oxidative stress (OS), and concomitant loss of the mitochondrial membrane potential $\left(\Delta \Psi_{\mathrm{m}}\right)$, activation of apoptogenic proteins, and DNA fragmentation, markers of apoptosis-a type of regulated cell death. Additionally, mutant ChLNs displayed $\mathrm{Ca}^{2+}$ flux dysregulation when challenged to acetylcholine (ACh) and deficient acetylcholinesterase (AChE) activity compared to wild type (WT) ChLNs most probably due to eA $\beta_{42}$ peptide. Taken together these observations suggest that PSEN1 E280A ChLNs display the typical neuropathological markers of $\mathrm{AD}$; therefore, mutant ChLNs provide a unique FAD model for screening of candidate molecule(s)/drug(s).

Due to the lack of effective therapies to date for $\mathrm{AD}$, the need for new drugs has become increasingly urgent. Phytocannabinoids, a group of biologically active compounds isolated from the plant Cannabis sativa [17], have been postulated to possess therapeutic potential for clinical purposes in AD [18]. Cannabis contains at least 120 kinds of cannabinoids mainly classified as $\Delta^{9}$-trans-tetrahydrocannabidiol (THC), cannabidiol (CBD), CBG (Cannabigerol), and CBN (Cannabinol), among others [19]. Biologically, cannabinoids, endocannabinoids (e.g., anandamide, 2-arachidonoylglycerol), and synthetic cannabimimetic compounds (e.g., CP55940) bind cannabinoid type 1 and 2 receptors $\left(\mathrm{CB}_{1} \mathrm{R} / \mathrm{CB}_{2} \mathrm{R}\right)$, two G-protein-coupled receptors (GPCR) [20, 21]. Interestingly, it has been shown in vitro that 9 out of 11 cannabinoids studied, including THC, were able to protect cells (e.g., MC65-a human neuron-like cell line, HT22 mouse hippocampal nerve cell line, primary cortical neurons from 18day-old rat embryos, BV2-a microglial cell line) in four distinct phenotypic neurodegeneration screening assays including proteotoxicity, loss of trophic support, OS, energy loss, and inflammation [22]. Outstandingly, cannabinoids were able to remove intraneuronal $A \beta$, reduce oxidative damage, and protect from the loss of energy or trophic support in neurons in which $\mathrm{CB}_{1}$ and $\mathrm{CB}_{2}$ receptors were lacking (e.g., MC65 and HT22 cells). Furthermore, $\mathrm{CB}_{1}$ agonists (e.g., CP55940) were also effective neuroprotective agents against $A \beta$ toxicity in MC65 neurons [22]. These data suggest that cannabinoids might be antioxidant and anti-amylogenic compounds through receptor-independent mechanisms in a cell- and species-specific manner [22-28]. Despite these observations, no data are available to establish whether cannabinoids might reverse the neuropathological markers, i.e., intracellular sA $\beta P P \beta f$ aggregation, hyperphosphorylation of tau protein, and DJ-1 oxidation in PSEN1 E280A ChLNs. Furthermore, it is not yet known whether cannabinoids might be able to block neuronal apoptosis, eA $\beta_{42}$, and/or prevent $\mathrm{Ca}^{2+}$ dysregulation in those mutant cholinergic neurons.

To get insight into these issues, we have selected the commercially available CP55940 ((-)-cis-3-[2Hydroxy-4-(1,1-dimethylheptyl)phenyl]-trans-4-(3hydroxypropyl)cyclohexanol, hereafter $\mathrm{CP}$ ), a $\mathrm{CB}_{1}$ and $\mathrm{CB}_{2}$ potent bicyclic analog of THC [29], to evaluate its effect on wild-type and PSEN1 E280A ChLNs concerning the intracellular sA $\beta P P \beta f$ accumulation, tau phosphorylation, OS, cell death, and $\mathrm{Ca}^{2+}$ neuronal dysfunction in ChLNs. We demonstrate for the first time that $\mathrm{CP}$ can protect $\mathrm{FAD}$ PSEN1 E280A ChLNs against neuronal structural 
damage and OS-induced cell death signaling and that it can reverse the cholinergic dysfunction in the presence of eA $\beta_{42}$ blocking agents (e.g., anti-A $\beta_{42}$ antibody $6 \mathrm{E} 10)$. These findings might favor the use of cannabinoids as potential lead compound candidates as a combined therapy for FAD.

\section{MATERIALS AND METHODS}

\section{Cholinergic-like neuron (ChLN) differentiation}

ChLN differentiation was performed according to [30]. The WT (TBC\# WJMSC-11) and PSEN1 E280A (TBC\# WJMSC-12) [16] MSCs were seeded at $1-1.5 \times 10^{4}$ cells $/ \mathrm{cm}^{2}$ in laminin-treated culture plates for $24 \mathrm{~h}$ in regular culture medium $(R C m)$. Then, the medium was removed, and cells were incubated in cholinergic differentiation medium (Cholinergic-N-Run medium, hereafter $\mathrm{Ch}-\mathrm{N}-\mathrm{Rm}$ ) containing DMEM/F-12 media 1:1 Nutrient Mixture (Gibco cat\# 10565018), $10 \mathrm{ng} / \mathrm{mL}$ basic fibroblast growth factor (bFGF) recombinant human protein (Gibco Cat\# 13256029), $50 \mu \mathrm{g} / \mathrm{mL}$ sodium heparin (Hep, Sigma-Aldrich cat\# H3393), $0.5 \mu \mathrm{M}$ all-trans retinoic acid, $50 \mathrm{ng} / \mathrm{ml}$ sonic hedgehog peptide $(\mathrm{SHH}$, Sigma cat\# SRP3156) and $1 \%$ FBS at $37^{\circ} \mathrm{C}$ for 7 days. After this process of transdifferentiation, the cells were labeled as WT PSEN1 or PSEN1 E280A ChLNs. Since $C h-N-R m$ contains several factors that might interfere with the experiment interpretation and measurements, WT PSEN1 and PSEN1 E280A ChLNs (obtained after 7 days in $C h-N-R m$ ) were left in regular culture medium $(R C m)$ for 4 additional days of post transdifferentiation.

\section{Immunofluorescence analysis}

For the analysis of markers of $\mathrm{AD}$, oxidative stress, and cell death, the cells treated under different conditions were fixed with $4 \%$ paraformaldehyde for $20 \mathrm{~min}$, followed by Triton X-100 (0.1\%) permeabilization and $10 \%$ bovine serum albumin (BSA) blockage. Cells were incubated overnight with primary antibodies against $\mathrm{APP}_{751}$ and/or protein amyloid $\beta_{1-42}$ (1:500; clone 6E10 cat\# 803014, Biolegend), total tau (1:500; t-Tau; cat\# T6402, Sigma), and phospho-tau (p-Tau, 1:500, Ser202/ Thr205, cat\# MN1020 (AT8), Thermo Fisher Scientific); and primary antibodies against oxidized DJ-1 (1:500; ox(Cys 106)DJ-1; spanning residue $\mathrm{C}^{106}$ of human PARK7/DJ1; oxidized to produce cysteine sulfonic $\left(\mathrm{SO}_{3}\right)$ acid; cat \# ab169520, Abcam). To assess cell death, we used primary antibodies against p53-upregulated modulator of apoptosis (1:500; PUMA, cat\# ab-9643, Abcam), p53 (1:500; cat\# MA5-12453, Millipore), phospho-c-Jun (1:250; c-Jun (S63/73) cat\# sc-16312, Santa Cruz), and caspase-3 (1:250; cat \# AB3623, Millipore). After exhaustive rinsing, we incubated the cells with secondary fluorescent antibodies (DyLight 488 and 594 horse anti-rabbit, -goat and -mouse, cat DI 1094, DI 3088 , and DI 2488, respectively) at 1:500. The nuclei were stained with $1 \mu \mathrm{M}$ Hoechst 33342 (Life Technologies), and images were acquired on a Floyd Cells Imaging Station microscope.

\section{Western blot analysis}

Cells were incubated as described above, detached with $0.25 \%$ trypsin and lysed in $50 \mathrm{mM}$ Tris- $\mathrm{HCl}$, $\mathrm{pH} 8.0$, with $150 \mathrm{mM}$ sodium chloride, $1.0 \%$ Igepal CA-630 (NP-40), and 0.1\% sodium dodecyl sulfate and a protease inhibitor cocktail (Sigma-Aldrich). All lysates were quantified using the bicinchoninic acid assay (Thermo Scientific cat \# 23225). Extracted samples ( $30 \mu \mathrm{g}$ of proteins) were heated at $95^{\circ} \mathrm{C}$ for $5 \mathrm{~min}$ in $2 \times$ SDS and $20 \times$ reducing agent (except for protein oxDJ-1) and loaded on to $12 \%$ gels at $120 \mathrm{~V}$ for $90 \mathrm{~min}$, and the bands were transferred onto nitrocellulose membranes (Hybond-ECL, Amersham Biosciences) at $270 \mathrm{~mA}$ for $90 \mathrm{~min}$ using an electrophoretic transfer system (BIO-RAD) according to Bio-Rad protocol (http://www.bio-rad.com/webroot/ web/pdf/lsr/literature/Bulletin_6376). The membranes were incubated overnight at $4{ }^{\circ} \mathrm{C}$ with anti$\mathrm{APP}_{751}$, total tau, phospho-Tau, ox $\left(\mathrm{Cys}^{106}\right) \mathrm{DJ} 1$, PUMA, p53, p-c-Jun, and caspase-3 primary antibodies (1:5000). The anti-actin antibody $(1: 1000$, cat \#MAB1501, Millipore) was used as an expression control. Secondary infrared antibodies (goat anti-rabbit IRDye ${ }^{\circledR}$ 680 RD, cat \#926-68071; donkey anti-goat IRDye ( 680 RD, cat \# 926-68074; and goat anti-mouse IRDye ${ }^{\circledR} 800 \mathrm{CW}$, cat \#92632270; LI-CORBiosciences) at 1:1000 were used for western blotting analysis, and data were acquired using Odyssey software. The determination of the aggregation state of $\mathrm{APP}_{751}$ (i.e., sA $\beta P P \beta f$ ) was performed by western analysis of SDS-PAGE as described above. The assessment was repeated three times in independent experiments.

\section{Analysis of cells}

\section{Assay protocol}

The methodology for both WT and PSEN1 E280A ChLNs cell culture assays was the same. Initial 
CP55940 screening was performed at least twice in triplicate between $10 \mathrm{nM}$ and $1 \mu \mathrm{M}$. Subsequently, CP55940 $(1 \mu \mathrm{M})$ was established as an optimal concentration for further experiments. ChLNs were divided in four groups: 1) untreated; 2) treated with SR141716 $\left(\mathrm{CB}_{1}\right.$ receptor inverse agonist $)$ and $\mathrm{SR} 144528\left(\mathrm{CB}_{2}\right.$ receptor inverse agonist $)$ at $1 \mu \mathrm{M}$ final concentration each (hereafter SR); 3) CP55940 (or CP); 4) RS + CP55940 (also named as SR + CP cocktail). To block eA $\beta_{42}$ [31], WT and mutant ChLNs were incubated four days with anti-A $\beta_{42}$ antibody $6 \mathrm{E} 10$ (1:300 in $R C m$ ) after differentiation in the presence or absence of $\mathrm{CP}$ or $\mathrm{CP}+\mathrm{RS}$.

\section{Evaluation of intracellular hydrogen peroxide $\left(\mathrm{H}_{2} \mathrm{O}_{2}\right)$ by fluorescence microscopy}

To determine the levels of intracellular $\mathrm{H}_{2} \mathrm{O}_{2}$, we used $2^{\prime}, 7^{\prime}$-dichlorofluorescein diacetate $(5 \mu \mathrm{M}$, DCFH2-DA; Invitrogen). ChLNs were left in $\mathrm{RCm}$ for 4 days. Then, the cells $\left(5 \times 10^{3}\right)$ were incubated with the $\mathrm{DCFH}_{2}-\mathrm{DA}$ reagent for $30 \mathrm{~min}$ at $37^{\circ} \mathrm{C}$ in the dark. Cells were then washed, and DCF fluorescence intensity was determined by analysis of fluorescence microscopy images. The assessment was repeated three times in independent experiments. The nuclei were stained with $0.5 \mu \mathrm{M}$ Hoechst 33342 staining compound. The assessment was repeated three times in independent experiments blind to the experimenter.

\section{Analysis of mitochondrial membrane potential $(\Delta \Psi m)$ by fluorescence microscopy}

The ChLNs were left in regular culture medium $(\mathrm{RCm})$ for 4 days. Then, the cells $\left(5 \times 10^{3}\right)$ were incubated with the passively diffusing and active mitochondria-accumulating dye deep red MitoTracker compound ( $20 \mathrm{nM}$, final concentration) for $20 \mathrm{~min}$ at room temperature in the dark (Invitrogen, cat \# M22426). Cells were then washed twice with PBS. MitoTracker fluorescence intensity was determined by analysis of fluorescence microscopy images. The assessment was repeated three times in independent experiments. The nuclei were stained with $0.5 \mu \mathrm{M}$ Hoechst 33342 staining compound. The assessment was repeated three times in independent experiments blind to the experimenter and flow cytometer analyst.

\section{Measurement of $A \beta_{42}$ peptide in culture medium}

The level of $A \beta_{1-42}$ peptide was measured according to a previous report [32] with minor modifications. Briefly, WT and PSEN1 E280A ChLNs were left in $\mathrm{RCm}$ for 4 days. Then, $100 \mu \mathrm{l}$ of con- ditioned medium was collected, and the levels of secreted $A \beta_{42}$ peptides were determined by a solidphase sandwich ELISA (Invitrogen, Cat\# KHB3544) following the manufacturer's instructions. The assessment was repeated 4 times in independent experiments blind to the experimenter.

\section{Intracellular calcium imaging}

Intracellular calcium $\left(\mathrm{Ca}^{2+}\right)$ concentration changes evoked by cholinergic stimulation were assessed according to $[33,34]$ with minor modifications. For the measurement, the fluorescent dye Fluo-3 (Fluo3 AM; Thermo Fisher Scientific, cat: F1242) was employed. The dye was dissolved in DMSO $(1 \mathrm{mM})$ to form a stock solution. Before the experiments, the stock solution was diluted in neuronal buffer solution (NBS buffer: $137 \mathrm{mM} \mathrm{NaCl}, 5 \mathrm{mM} \mathrm{KCl}, 2.5 \mathrm{mM}$ $\mathrm{CaCl}_{2}, 1 \mathrm{mM} \mathrm{MgCl}$, $\mathrm{pH} 7.3$, and $22 \mathrm{mM}$ glucose). The working concentration of the dye was $2 \mu \mathrm{M}$. The WT and PSEN1 E280A ChLNs were incubated for $30 \mathrm{~min}$ at $37^{\circ} \mathrm{C}$ with the dye-containing NBS and then washed five times. Intracellular $\mathrm{Ca}^{2+}$ transients were evoked by acetylcholine ( $1 \mathrm{mM}$ final concentration) at 4 days post differentiation. The measurements were carried out using the $20 \times$ objective of the microscope. Several regions of interest (ROIs) were defined in the visual field of the camera. One of the ROIs was cellfree, and the fluorescence intensity measured here was considered background fluorescence $\left(F_{b g}\right)$. The time dependence of the fluorescence emission was acquired, and the fluorescence intensities (hence the $\mathrm{Ca}^{2+}$ levels) were represented by pseudo colors. To calculate the changes of the average $\mathrm{Ca}^{2+}$-related fluorescence intensities, the $\mathrm{F}_{\mathrm{bg}}$ value was determined from the cell-free ROI, and then the resting fluorescence intensities $\left(\mathrm{F}_{\text {rest }}\right)$ of the cell-containing ROIs were obtained as the average of the points recorded during a consecutive period of $10 \mathrm{~s}$ before the addition of acetylcholine. The peaks of the fluorescence transients were found by calculating the average of six consecutive points and identifying those points that gave the highest average value $\left(\mathrm{F}_{\max }\right)$. The amplitudes of the $\mathrm{Ca}^{2+}$-related fluorescence transients were expressed relative to the resting fluorescence $(\Delta F / F)$ and were calculated by the following formula: $\Delta F / F=\left(F_{\text {max }}-F_{\text {rest }}\right) /\left(F_{\text {rest }}-F_{\text {bg }}\right)$. For the calculation of the fluorescence intensities, ImageJ was used. The terms fluorescence intensity was used as an indirect indicator of intracellular $\mathrm{Ca}^{2+}$ concentration. The assessment was repeated three times in independent experiments blind to the experimenter. 


\section{Photomicrography and image analysis}

Light microscopy photographs were taken using a Zeiss Axiostart 50 Fluorescence Microscope equipped with a Canon PowerShot G5 digital camera (Zeiss Wöhlk-Contact-Linsen, Gmb Schcönkirchen, Germany), and fluorescence microscopy photographs were taken using a Zeiss Axiostart 50 Fluorescence Microscope equipped with a Zeiss AxioCam $\mathrm{Cm} 1$ and (Zeiss Wöhlk-Contact-Linsfluoreen, Gmb Schcönkirchen, Germany) and Floyd Cells Imaging Station microscope. Fluorescence images were analyzed by ImageJ software (http://imagej.nih.gov/ij/). The figures were transformed into 8-bit images, and the background was subtracted. The cellular measurement ROIs were drawn around the nucleus (for the case of transcription factors and apoptosis effectors) or overall cells (for cytoplasmic probes), and the fluorescence intensity was subsequently determined by applying the same the threshold for cells in the control and treatment conditions. Mean fluorescence intensity (MFI) was obtained by normalizing total fluorescence to the number of nuclei.

\section{Data analysis}

In this experimental design, a vial of MSCs was thawed, cultured and the cell suspension was pipetted at a standardized cellular density of $2.6 \times 10^{4}$ cells/ $\mathrm{cm}^{2}$ into different wells of a 24 -well plate. Cells (i.e., the biological and observational unit [35]) were randomized to wells by simple randomization (sampling without replacement method), and then wells (i.e., the experimental units) were randomized to treatments by a similar method. Experiments were conducted in triplicate wells. The data from individual replicate wells were averaged to yield a value of $n=1$ for that experiment and this was repeated on three occasions blind to the experimenter and/ or flow cytometer analyst for a final value of $n=3$ [35]. Based on the assumption that the experimental unit (i.e., the well) data comply with the independence of observations, the dependent variable is normally distributed in each treatment group (Shapiro-Wilk test), and variances are homogeneous (Levene's test), the statistical significance was determined by one-way analysis of variance (ANOVA) followed by Tukey's post hoc comparison calculated with GraphPad Prism 5.0 software. Differences between groups were only deemed significant when a $p$-value of $<0.05(*),<0.001\left(^{* *}\right)$ and $\left.<0.001{ }^{* * *}\right)$. All data are illustrated as the mean \pm S.D.

\section{RESULTS}

CP55940 restores the mitochondrial membrane potential $\left(\triangle \Psi_{\mathrm{m}}\right)$ and blunts generation of ROS in PSEN1 E280A ChLNs in an independent concentration fashion

Previously, it has been shown that PSEN 1 E280A ChLNs present aggregation of sA $\beta P P \beta f$, endogenously generated OS, and loss of $\Delta \Psi_{\mathrm{m}}$ as the earliest neuropathological markers in mutant ChLNs [16]. Therefore, we initially determined whether CP could recover $\Delta \Psi_{\mathrm{m}}$ and scavenge ROS in those cells. To this aim, cholinergic cells were exposed to increasing concentrations of $\mathrm{CP}$. As shown in Fig. 1A'-E', CP did not affect $\Delta \Psi_{\mathrm{m}}$ in wild type ChLNs (Fig. 1A-E, K). However, it significantly increased the $\Delta \Psi_{\mathrm{m}}$ in PSEN1 E280A ChLNs in a concentration-independent fashion (Fig. 1F'-J'). Accordingly, we found $500 \mathrm{nM}-1000 \mathrm{nM}(=1 \mu \mathrm{M})$, but not low concentrations $(10,100 \mathrm{nM})$, as the maximal optimal concentrations to raise $\Delta \Psi_{\mathrm{m}}$ in mutant cells (Fig. 1F-J, K). Figure 1 shows mutant ChLNs (Fig. 1F") but no WT ChLNs (Fig. 1A") endogenously produce ROS. CP blunted ROS yield in mutant ChLNs (Fig. 1G"-J") compared to WT ChLNs (Fig. 1B"-E") in an independent concentration fashion. Since $\mathrm{CP}(1 \mu \mathrm{M})$ recovered $\Delta \Psi_{\mathrm{m}}$ to control levels and completely diminished ROS in mutant ChLNs (Fig. 1K, L), we selected this concentration for further experiments.

\section{CP55940 restores $\Delta \Psi_{\mathrm{m}}$ in a $C B_{1}$ receptor-independent manner but diminishes ROS production partially dependent on $C B_{1}$ receptors in PSEN1 E280A ChLNs}

We wanted to establish whether the neuroprotective effect on mitochondria and antioxidant activity of $\mathrm{CP}$ was due to interaction with $\mathrm{CB}_{1}$ Rs. Although these receptors are expressed in cholinergic neurons [36] and $\mathrm{CP}$ is a $\mathrm{CB}_{1}$ and $\mathrm{CB}_{2}$ receptor agonist, we used both potent and highly specific $\mathrm{CB}_{1}$ and $\mathrm{CB}_{2}$ receptor inverse agonist SR141716 and SR144528 (hereafter SR at $1 \mu \mathrm{M}$ each) only or with $\mathrm{CP}$ agonist (i.e., $\mathrm{SR}+\mathrm{CP}$ cocktail) to avoid ambiguous observations. Figure 2 shows that while SR only neither affects $\Delta \Psi_{\mathrm{m}}$ in wild type ChLNs (i.e., high $\Delta \Psi_{\mathrm{m}}$ Fig. 2C) nor in mutant ChLNs (i.e., low $\Delta \Psi_{\mathrm{m}}$ Fig. 2D) when compared to untreated neurons 

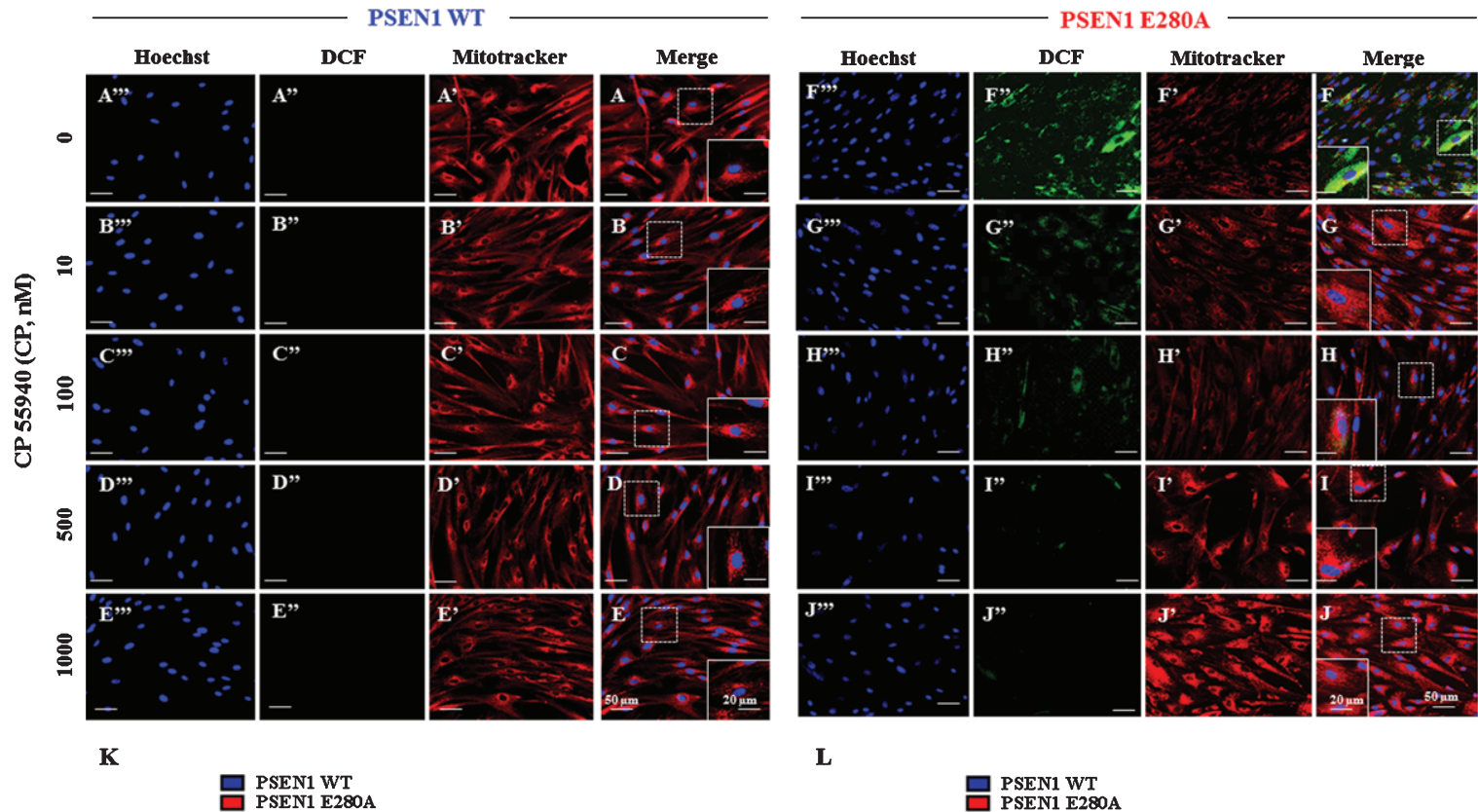

$\mathbf{L}$
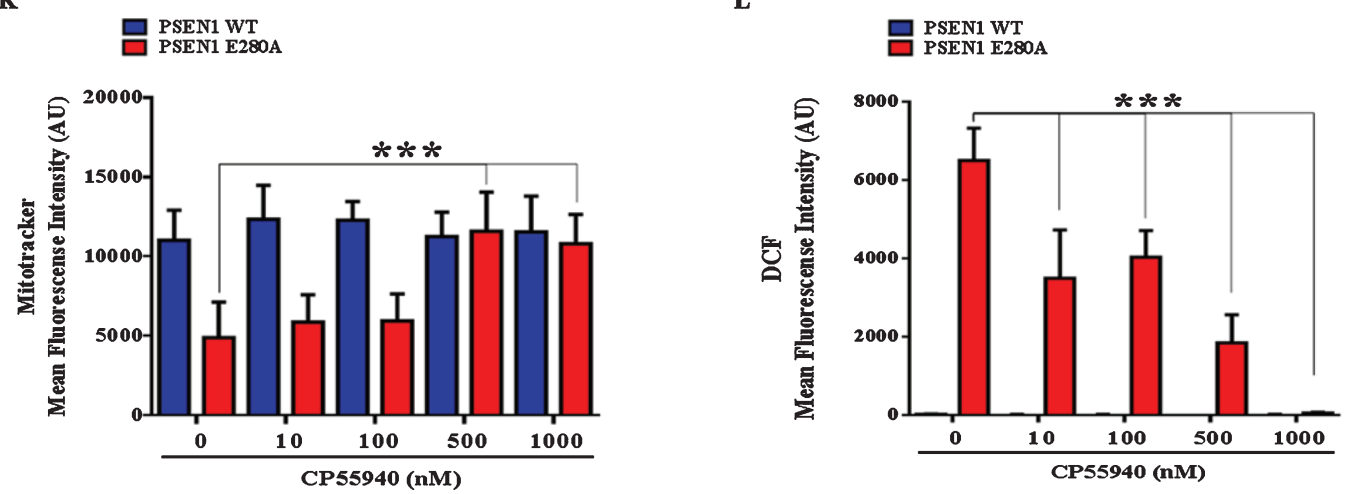

Fig. 1. CP55940 restores the mitochondrial membrane potential $\left(\Delta \Psi_{\mathrm{m}}\right)$ and reduces the levels of intracellular reactive oxygen species independent of its concentration in PSEN1 E280A ChLNs. After 7 days of transdifferentiation, WT PSEN1 and PSEN1 E280A ChLNs were left untreated or treated with $\mathrm{CP}$ at increasing concentrations $(0,10,100,500$, and $1000 \mathrm{nM})$ in regular culture medium (RCm) for 4 days. Representative MitoTracker (A'-J'), DCF (A"-J"), Hoechst (A"'-J"'), and merge (A-J) pictures of WT PSEN1 and PSEN1 E280A ChLNs treated as described. K) Quantification of MitoTracker fluorescence intensity. L) Quantification of DCF fluorescence intensity. Data are expressed as the mean $\pm \mathrm{SD} ;{ }^{*} \mathrm{p}<0.05 ;{ }^{* *} \mathrm{p}<0.01 ;{ }^{* * *} \mathrm{p}<0.001$. The histograms and figures represent 1 out of 3 independent experiments. Image magnification, $200 \times$. Inset magnification, $800 \times$.

(Fig. 2A, B), CP (Fig. 2F) or $\mathrm{CP}+\mathrm{SR}$ (Fig. 2H) significantly increased the $\Delta \Psi_{\mathrm{m}}$ in mutant ChLNs (Fig. 2I). Neither CP nor the cocktail altered $\Delta \Psi_{\mathrm{m}}$ in WT ChLNs (Fig. 2E, G, I). However, analysis of ROS disappearance in ChLNs shows that while CP only almost completely scavenged ROS in mutant ChLNs (Fig. 2J), the SR $+\mathrm{CP}$ cocktail diminished ROS by almost half of the value of untreated or treated with SR only in PSEN1 E280A ChLNs (Fig. 2J). WT ChLNs produced no detectable ROS in any experimental condition (Fig. 2J). Of note, SR only treatment showed no effect in $\Delta \Psi_{\mathrm{m}}$ and ROS conditions in both WT (Fig. 2I) and mutant ChLNs (Fig. 2J).

\section{CP55940 reduces intracellular $s A \beta P P \beta f$ aggregation in a $C B_{1} R s$-independent fashion but it reduces oxidized DJ-1 partially dependent of $C B_{1}$ Rs in PSEN1 E280A ChLNs}

Next, we assessed whether CP could inhibit intracellular aggregation of sA $\beta P P \beta f$ and avoid oxidation of the stress sensor protein DJ-1. To this aim, WT and mutant ChLNs were left untreated or exposed to $\mathrm{CP}$ in the absence or presence of SR. Western blot analysis revealed that $\mathrm{CP}$ only or with $\mathrm{SR}$ reduced the aggregation of $\mathrm{sA} \beta \mathrm{PP} \beta \mathrm{f}$ in a $\mathrm{CB}_{1}$ Rs-independent manner (Fig. 3A, B) but blunted the oxidation of 

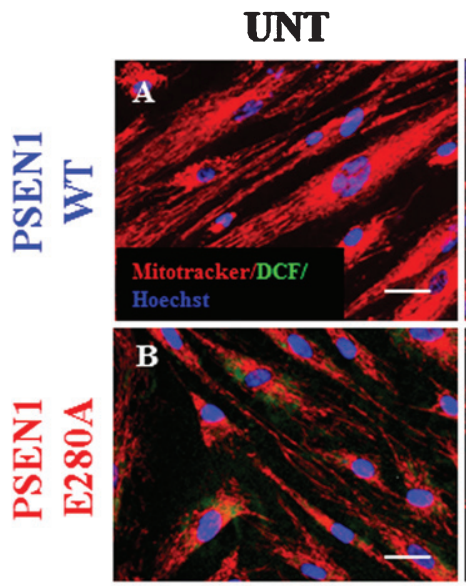

I

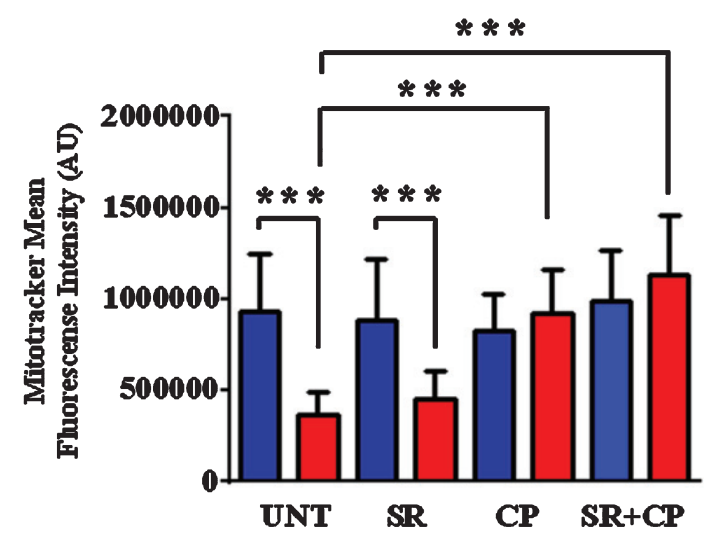

PSEN1 WT
SR
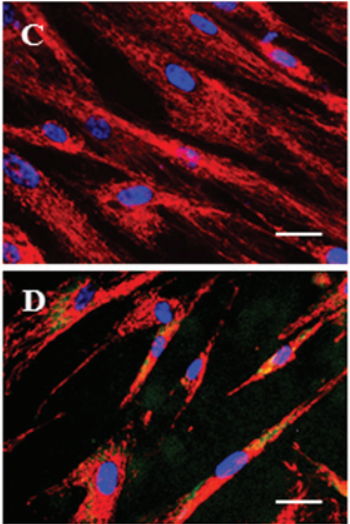

$\mathbf{C P}$

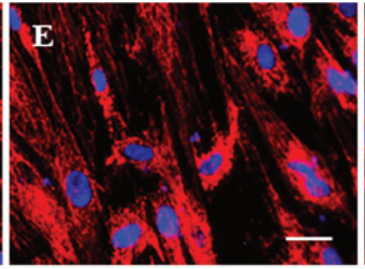

$\mathbf{F}$

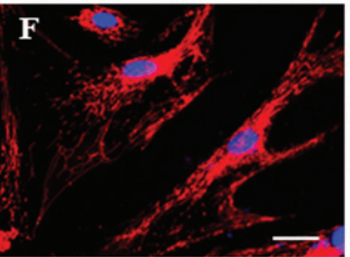

$\mathbf{S R}+\mathbf{C P}$

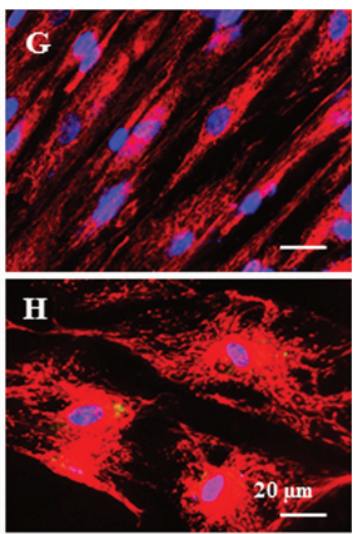

$* * *$
$\mathbf{J}$

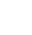

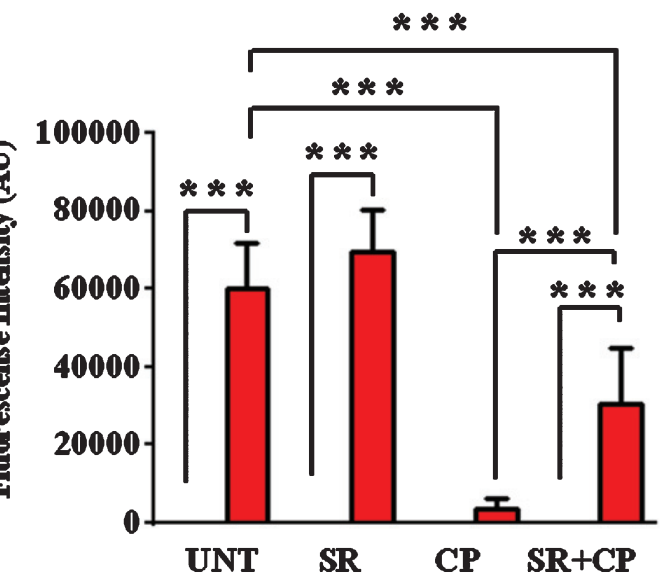

$\square$ PSEN1 WT $\square$ PSEN1 E280A

Fig. 2. CP55940 augments the $\Psi_{\mathrm{m}}$ independent of $\mathrm{CB}_{1} \mathrm{R}$ but reduced the levels of intracellular reactive oxygen species partially dependent on those receptors in PSEN1 E280A ChLNs. After 7 days of transdifferentiation, WT PSEN1 and PSEN1 E280A ChLNs were left untreated or treated with SR, CP, or SR + CP in RCm for 4 days. A-H) Representative MitoTracker/DCF/Hoechst merge pictures of WT PSEN1 and PSEN1 E280A ChLNs treated as described. I) Quantification of MitoTracker fluorescence intensity. J) Quantification of DCF fluorescence intensity. Data are expressed as the mean $\pm \mathrm{SD} ;{ }^{*} \mathrm{p}<0.05 ;{ }^{* *} \mathrm{p}<0.01 ;{ }^{* * *} \mathrm{p}<0.001$. The histograms and figures represent 1 out of 3 independent experiments. Image magnification, $400 \times$.

DJ-1 partially dependent of $\mathrm{CB}_{1}$ Rs (Fig. 3A, C). As expected, WT ChLNs remained unaltered to $\mathrm{CP}$ and to the cocktail exposure. Neither sA $\beta P P \beta f$ nor oxidized DJ-1 were detected in those neurons (Fig. 3A-C). These results were confirmed by fluorescent microscopy (Fig. 3D-M).

\section{CP55940 blocks apoptosis in a $C B_{1}$ Rs-independent manner in PSEN1 E280A ChLNs}

Cell death by apoptosis is a prominent feature in mutant ChLNs [16]. We used, therefore, the activation of the transcription factors p53 and c-Jun, pro-apoptotic $\mathrm{BH} 3$-only protein PUMA, and protease caspase-3 as apoptosis markers to examine the effect of CP and/or SR plus CP on those neuronal cells. Effectively, we confirmed that ChLNs displayed high levels of protein c-Jun (Fig. 4A, B), p53 (Fig. 4A, C), PUMA (Fig. 4A, D), and caspase-3 (Fig. 4A, E) in mutant but not in WT ChLNs (Fig. 4A-E). No significant difference was found between untreated and SR treatment for all the apoptosis markers in both types of cells. However, $\mathrm{CP}$ only or $\mathrm{CP}+\mathrm{SR}$ significantly reduced c-Jun (Fig. 4A, B), p53 (Fig. 4A, C), PUMA (Fig. 4A, D), and caspase-3 (Fig. 4A, E) in PSEN1 E280A neurons when compared to untreated cells or WT ChLNs. Interestingly, mutant neurons exposed to 
$\mathbf{A}$

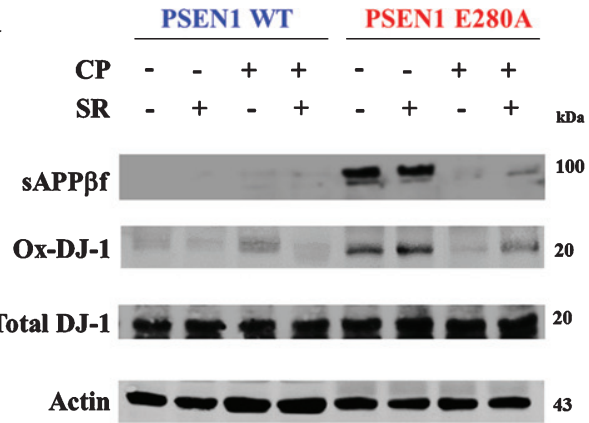

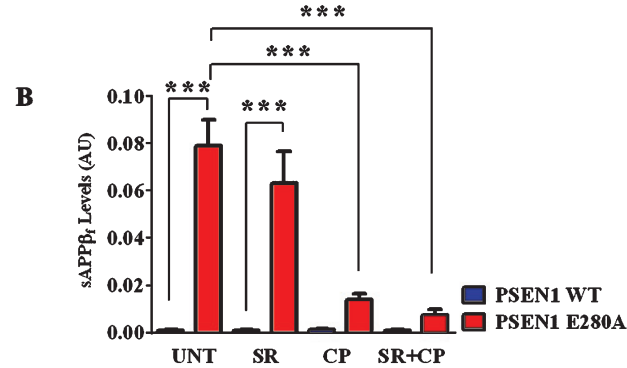
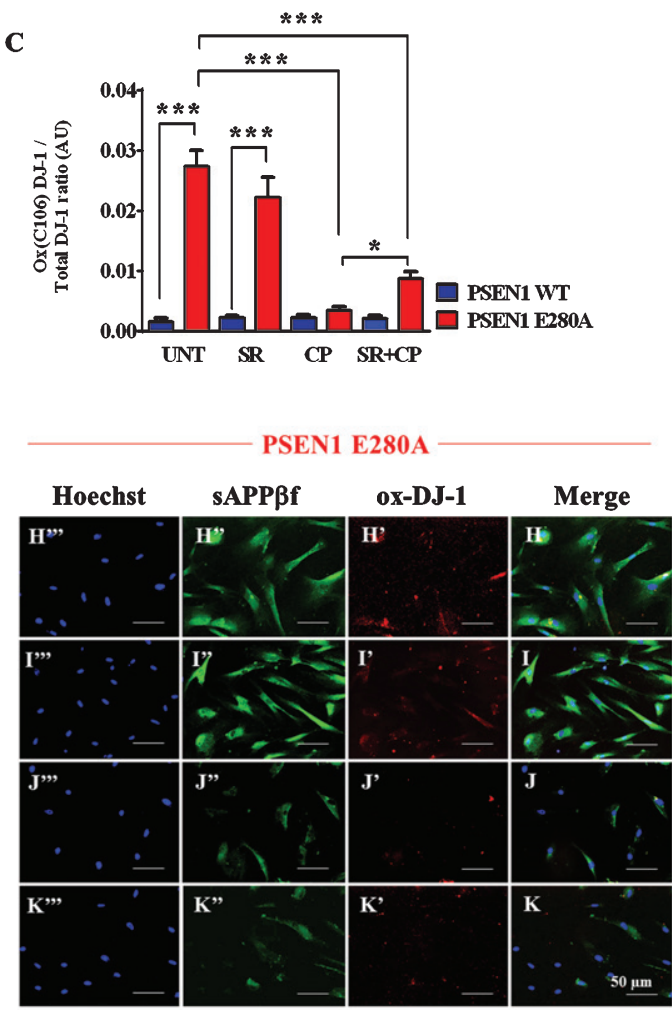

$\mathbf{M}$

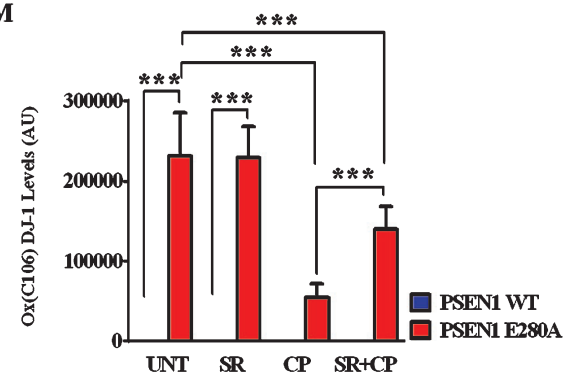

Fig. 3. CP55940 reduced intracellular sAßPP $\beta f$ and oxidized DJ-1 independent of $\mathrm{CB}_{1}$ Rs in PSEN1 E280A ChLNs. After 7 days of transdifferentiation, WT PSEN1 and PSEN1 E280A ChLNs were left untreated or treated with SR, CP, or SR + CP in RCm for 4 days. Further, the proteins in the extracts were blotted with primary antibodies against $A \beta_{42}$, oxDJ-1Cys ${ }^{106}$, and actin proteins. The intensities of the western blot bands shown in (A) were measured (B, C) by an infrared imaging system (Odyssey, LI-COR), and the intensity was normalized to that of actin. Additionally, cells were double-stained as indicated in the figure (D-K) with primary antibodies against oxDJ$1 \mathrm{Cys}^{106}$ (red; D'-K') and $\mathrm{APP}_{751} / \mathrm{A}_{42}$ (green; D"- K"). The nuclei were stained with Hoechst 33342 (blue; D"'- K"'). L) Quantification of $A \beta_{42}$ fluorescence intensity. M) Quantification of oxDJ-1Cys ${ }^{106}$ fluorescence intensity. Data are expressed as the mean $\pm \mathrm{SD} ;{ }^{*} \mathrm{p}<0.05$; ${ }^{* *} \mathrm{p}<0.01 ;{ }^{* * *} \mathrm{p}<0.001$. The blots and figures represent 1 out of 3 independent experiments. Image magnification, $200 \times$. 
A

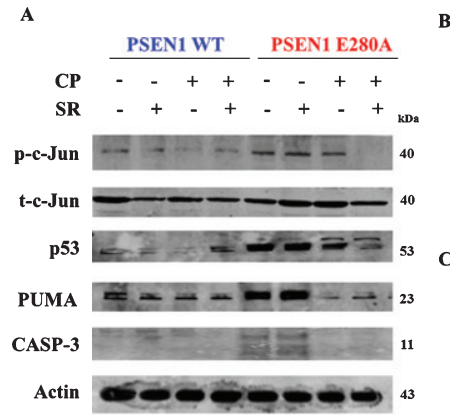

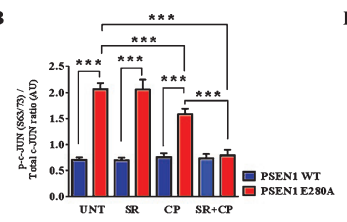

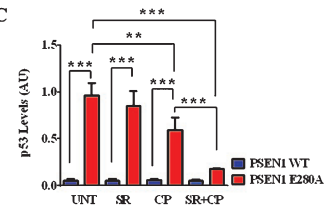

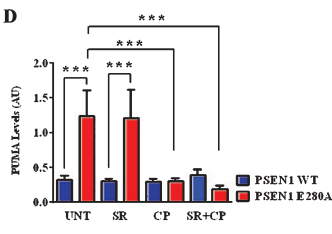

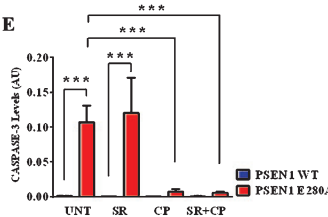

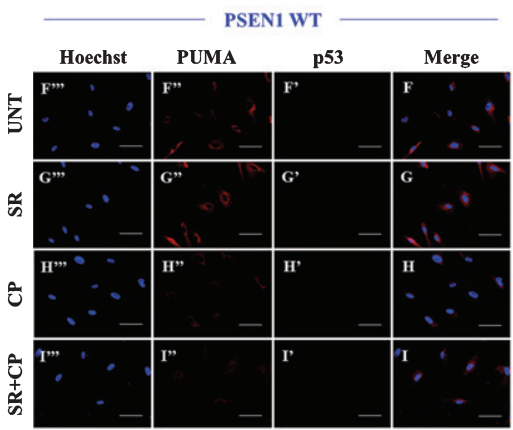
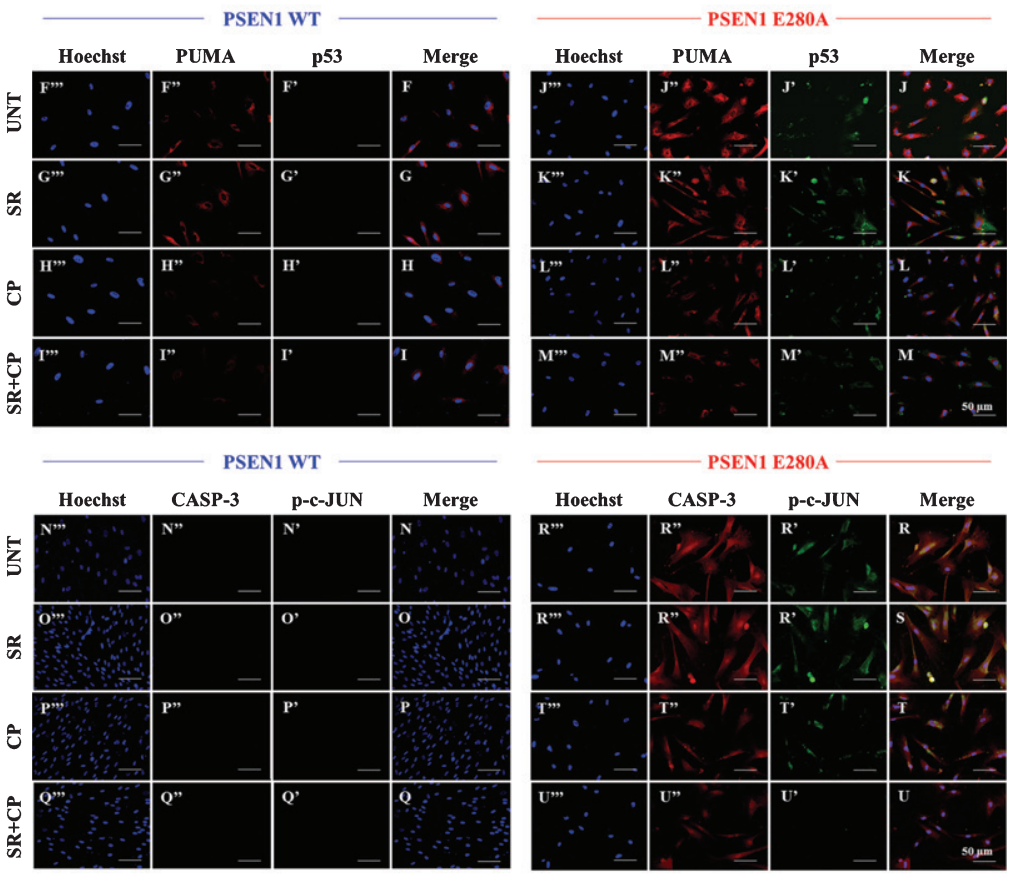

V

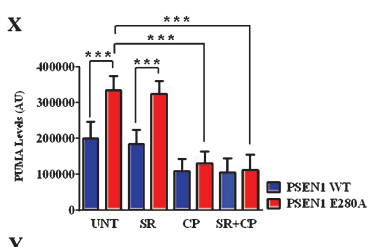

W
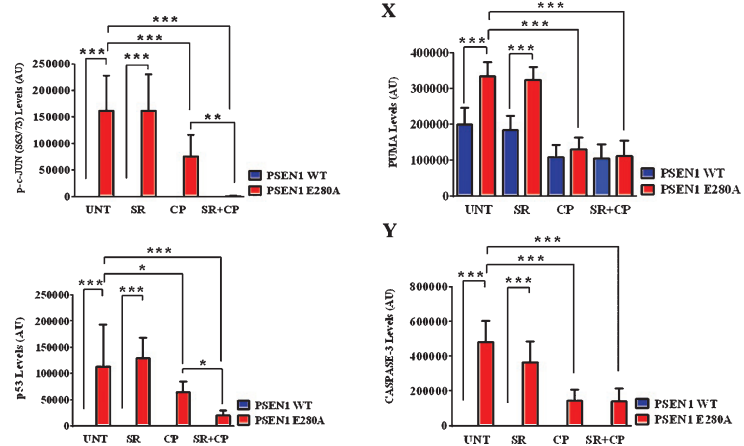

Fig. 4. CP55940 reduced the activation of p53, PUMA, c-Jun, and caspase-3 independent of $\mathrm{CB}_{1}$ Rs signaling in PSEN1 E280A ChLNs. After 7 days of transdifferentiation, WT PSEN1 and PSEN1 E280A ChLNs were left Untreated or treated with SR, CP, or SR + CP in regular culture medium for 4 days. After this time, the proteins in the extracts were blotted with primary antibodies against phosphorylated c-Jun (p-c-JUN)/total c-Jun, p53, PUMA, caspase-3 (CASP-3) and actin proteins. The intensities of the western blot bands shown in (A) were measured (B-E) by an infrared imaging system (Odyssey, LI-COR), and the intensity was normalized to that of actin. Additionally, cells were double-stained as indicated in the figure (F-U) with primary antibodies against p53 (green; F'-M'), PUMA (red; F'-M"), c-JUN (green; N'-U'), and CASP-3 (red; N"-U"). The nuclei were stained with Hoechst 33342 (blue; F"'-U"'). V-X) Quantification of c-JUN (V), p53 (W), PUMA (X), and CASP-3 (Y) fluorescence intensity. Data are expressed as the mean \pm SD; ${ }^{*} \mathrm{p}<0.05 ;{ }^{* *} \mathrm{p}<0.01 ;{ }^{* * *} \mathrm{p}<0.001$. The blots and figures represent 1 out of 3 independent experiments. Image magnification, $200 \times$. 
$\mathrm{CP}+\mathrm{SR}$ displayed almost basal levels of all proteins comparable to WT ChLNs. These observations were confirmed by fluorescent microscopy (Fig. 4F-Y).

\section{CP55940 inhibits tau phosphorylation in a $C B_{1}$ Rs-independent fashion PSEN1 E280A ChLNS}

It has been established that intracellular sA $\beta P P \beta f$ induce phosphorylation of tau [16]. We then investigated whether $\mathrm{CP}$ could inhibit tau phosphorylation in PSEN1 E280A ChLNs. As shown in Fig. 5, while the level of tau phosphorylation was detected to a similar extend in WT ChLNs under any experimental conditions (Fig. 5A, B), CP or $\mathrm{CP}+\mathrm{SR}$ cocktail dramatically reduced phosphorylation of protein tau when compared to untreated or SR only treatment in mutant ChLNs (Fig. 5A, B). No statistically differences were observed between $\mathrm{CP}$ and $\mathrm{CP}+\mathrm{SR}$ treatments in mutant ChLNs (Fig. 5B). These observations were confirmed by fluorescent microscopy (Fig. 5C-K).

\section{CP55940 reduces the levels of eA $\beta_{42}$ protein fragment independent of $C B_{1}$ Rs in PSEN 1 E280A ChLNs}

Based on the observation that $\mathrm{CP}$ inhibited the intracellular aggregation of sA $\beta P \beta \beta$ (see Fig. 3), we assessed whether $\mathrm{CP}$ could have the same effect on eA $\beta_{42}$ [16]. Effectively, CP and CP + SR but not SR only significantly diminished the amounts of eA $\beta_{42}$ compared to untreated neurons in mutant ChLNs according to the ELISA technique (Fig. 6). No statistically differences were observed between $\mathrm{CP}$ and $\mathrm{CP}+\mathrm{SR}$ treatments in mutant ChLNs (Fig. 6). The amount of eA $\beta_{42}$ was not affected by any of the treatments in WT ChLNs (Fig. 6).

\section{CP55940 does not recover $\mathrm{Ca}^{2+}$ dysregulation in PSEN1 E280A ChLNs}

The above observations prompted us to test whether $\mathrm{CP}$ could ameliorate the physiological response of mutant ChLNs to ACh neurotransmitter stimuli. As expected, ACh induced a transient elevation of intracellular $\mathrm{Ca}^{2+}$ in WT ChLNs (control, the average maximum fluorescence change $(\Delta \mathrm{F} / \mathrm{F})$ was $3.95 \pm 0.19$ at $10 \mathrm{~s}(\mathrm{n}=20 \mathrm{ChLN}$ cells imaged, $\mathrm{N}=3$ dishes were used as a standard condition in this and following experiments) according to cytoplasmic $\mathrm{Ca}^{2+}$ responses to Fluo-3-mediated imaging (Fig. 7A, E). We found no statistical differences between $\mathrm{SR}$ (Fig. 7B, $\mathrm{E}, \Delta \mathrm{F} / \mathrm{F}=5.05 \pm 0.35$ ), $\mathrm{SR}+\mathrm{CP} \quad$ (Fig. 7D, $\mathrm{E} ; \quad \Delta \mathrm{F} / \mathrm{F}=4.31 \pm 0.26)$ and untreated conditions (Fig. 7E). In contrast, CP only and ACh significantly depressed intracellular $\mathrm{Ca}^{2+}$ (by -68\%) in WT ChLNs (Fig. 7C, E, $\Delta \mathrm{F} / \mathrm{F}=2.35 \pm 0.12$ ). When mutant neurons were exposed to ACh only (Fig. 7F, J, $\Delta \mathrm{F} / \mathrm{F}=0.02 \pm 0.00$ ) and $\mathrm{CP}$ (Fig. $7 \mathrm{H}, \mathrm{J}, \Delta \mathrm{F} / \mathrm{F}=0.06 \pm 0.00)$, mutant cells were irresponsive to both stimuli (Fig. 7J). Interestingly, while SR only slightly increased intracellular $\mathrm{Ca}^{2+}$ (Fig. 7G, J, $\Delta \mathrm{F} / \mathrm{F}=0.63 \pm 0.07$ ), the $\mathrm{CP}+\mathrm{SR}$ cocktail and ACh increased inflow $\mathrm{Ca}^{2+}$ (Fig. 7H, $\mathrm{J}, \Delta \mathrm{F} / \mathrm{F}=3.32 \pm 0.23$ ) in PSEN 1 E280A ChLNs to similar extend as $\left[\mathrm{Ca}^{2+}\right] \mathrm{i}$ in WT ChLNs (Fig. 7E, J).

\section{Anti-A $\beta_{42}$ antibodies completely recuperate $\mathrm{Ca}^{2+}$ influx in PSEN1 E280A ChLNs}

Since PSEN1 E280A ChLNs response to ACh decline in a time-dependent fashion [16], and since SR alone treatment was innocuous for WT and E280A ChLNs, we evaluated whether early inhibition of $\mathrm{e} A \beta_{42}$ by anti-A $\beta$ antibodies could ameliorate the mutant ChLNs response to $\mathrm{ACh}$ under $\mathrm{CP}$ and $\mathrm{CP}+\mathrm{SR}$ treatments. As shown in Fig. 8, incubation of WT with anti-A $\beta$ antibody 6 E10 only (Fig. 8A, D; $\Delta \mathrm{F} / \mathrm{F}=4.27 \pm 0.21)$ or in the presence of $\mathrm{CP}(\mathrm{Fig} .8 \mathrm{~B}$, $\mathrm{D} ; \Delta \mathrm{F} / \mathrm{F}=3.11 \pm 0.25$ ) or $\mathrm{CP}+\mathrm{SR}$ (Fig. $8 \mathrm{C}, \mathrm{D}$; $\Delta \mathrm{F} / \mathrm{F}=4.01 \pm 0.20)$ showed similar transient intracellular $\mathrm{Ca}^{2+}$. We found no statistical differences between those treatments (Fig. 8D). Remarkably, $\mathrm{ACh}$ and the anti-A $\beta$ antibody $6 \mathrm{E} 10$ completely recovered $\mathrm{Ca}^{2+}$ influx in mutant $\mathrm{ChLNs}$ (Fig. 8E, $\mathrm{H} ; \Delta \mathrm{F} / \mathrm{F}=3.37 \pm 0.20)$. The anti-A $\beta$ antibody $6 \mathrm{E} 10$ and $\mathrm{CP}$ (Fig. 8F, H; $\Delta \mathrm{F} / \mathrm{F}=5.78 \pm 0.87$ ) and antibody $+\mathrm{CP}+\mathrm{SR}($ Fig. $8 \mathrm{G}, \mathrm{H} ; \Delta \mathrm{F} / \mathrm{F}=5.93 \pm 0.29)$ dramatically induced a transient elevation of intracellular $\mathrm{Ca}^{2+}$ in mutant ChLNs (Fig. 8H).

\section{DISCUSSION}

In the present investigation, we demonstrate that $\mathrm{CP}$ inhibits the aggregation of (i)sA $\beta P P \beta f$, and $\mathrm{p}$ Tau, increases $\Delta \Psi_{\mathrm{m}}$, inhibits the generation of ROS and oxidation of DJ-1Cys ${ }^{106}$ SH to DJ-1Cys ${ }^{106}$ $\mathrm{SO}_{3}$, blocks the activation of the transcription factor p53 and c-Jun, pro-apoptotic protein PUMA, and protease caspase-3-all markers of cell death by apoptosis, and reduce eA $\beta_{42}$ in a $\mathrm{CB}_{1} \mathrm{R}$-dependent and-independent fashion in PSEN1 E280A ChLNs, used as a neuronal cell model of FAD [16]. Although 
$\mathbf{A}$

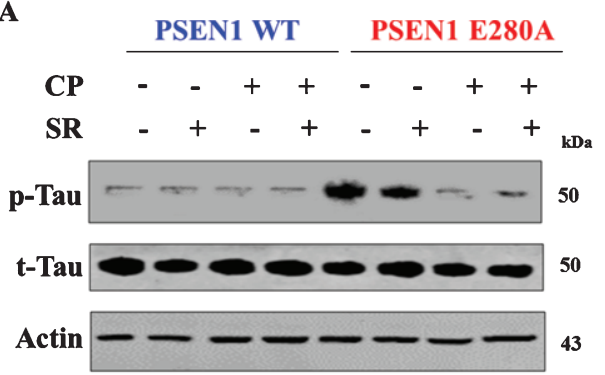

B

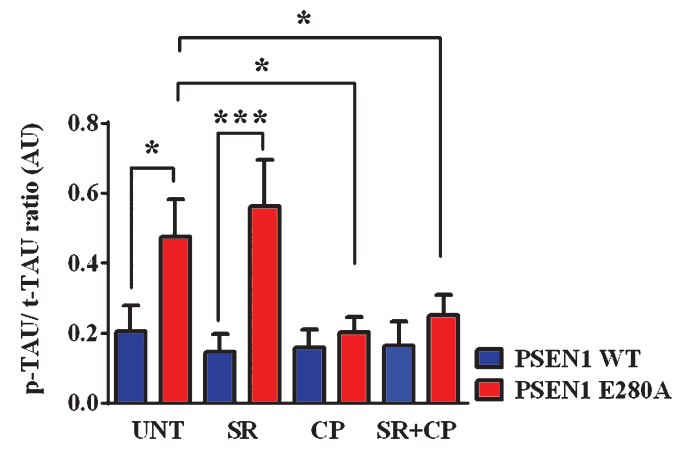

PSEN1 E280A

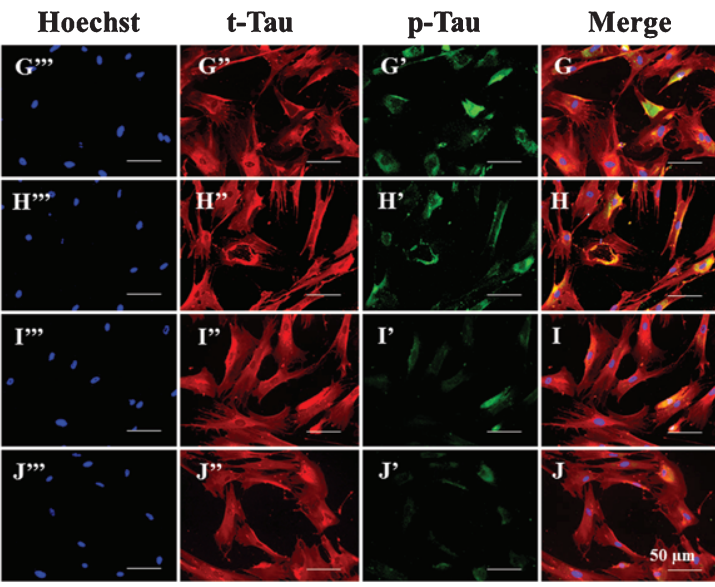

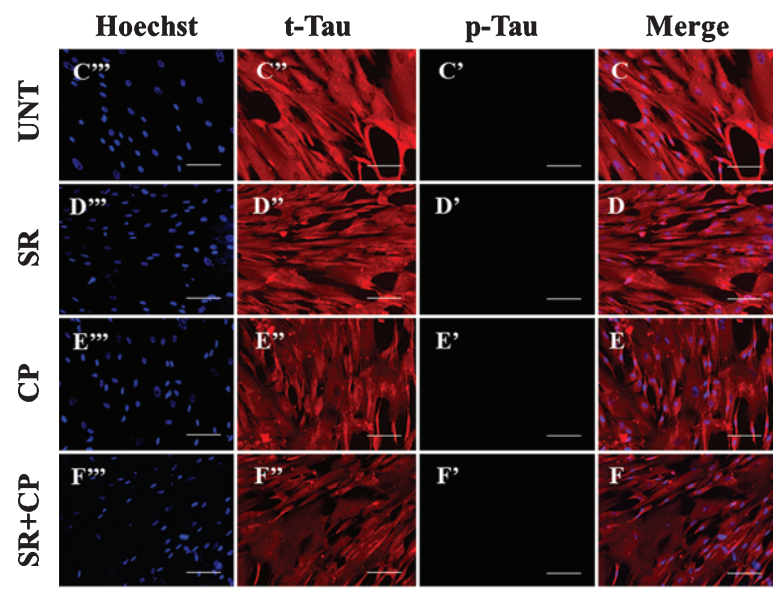

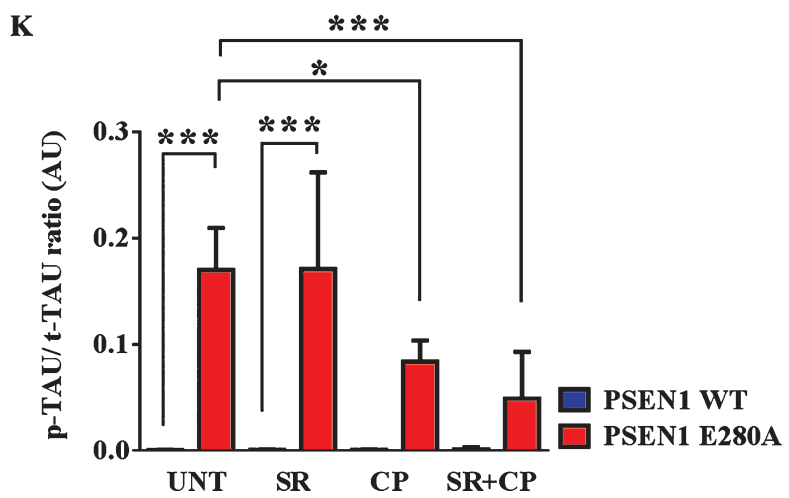

Fig. 5. CP55940 reduced the phosphorylation of tau protein independent of $\mathrm{CB}_{1}$ Rs in PSEN1 E280A ChLNs. After 7 days of transdifferentiation, WT PSEN1 and PSEN1 E280A ChLNs were left untreated or treated with SR, CP, or SR + CP in regular culture medium for 4 days. After this time, the proteins in the extracts were blotted with primary antibodies against phosphorylated tau (p-Tau), total tau (t-Tau), and actin proteins. The intensities of the western blot bands shown in (A) were measured (B) by an infrared imaging system (Odyssey, LI-COR), and the p-Tau/t-Tau ratio was normalized to that of actin. Additionally, cells were double-stained as indicated in the figure (C-J) with primary antibodies against p-Tau (green; C'-J') and t-Tau (red; C"-J"). The nuclei were stained with Hoechst 33342 (blue; C"'-J"'). K) Quantification of the $\mathrm{p}-\mathrm{Tau} / \mathrm{t}-\mathrm{Tau}$ fluorescence ratio. Data are expressed as the mean $\pm \mathrm{SD} ;{ }^{*} \mathrm{p}<0.05 ;{ }^{* *} \mathrm{p}<0.01 ;{ }^{* * *} \mathrm{p}<0.001$. The blots and figures represent 1 out of 3 independent experiments. Image magnification, 200×.

$\mathrm{CP}$ was unable to reverse the $\mathrm{Ca}^{2+}$ influx dysregulation as a response to $\mathrm{ACh}$ stimuli, it is demonstrated that CP affects several cellular molecular targets.
Several observations support these assumptions. First, in agreement with previous work [27], we found that $\mathrm{CP}$ reduced OS by directly scavenging ROS 


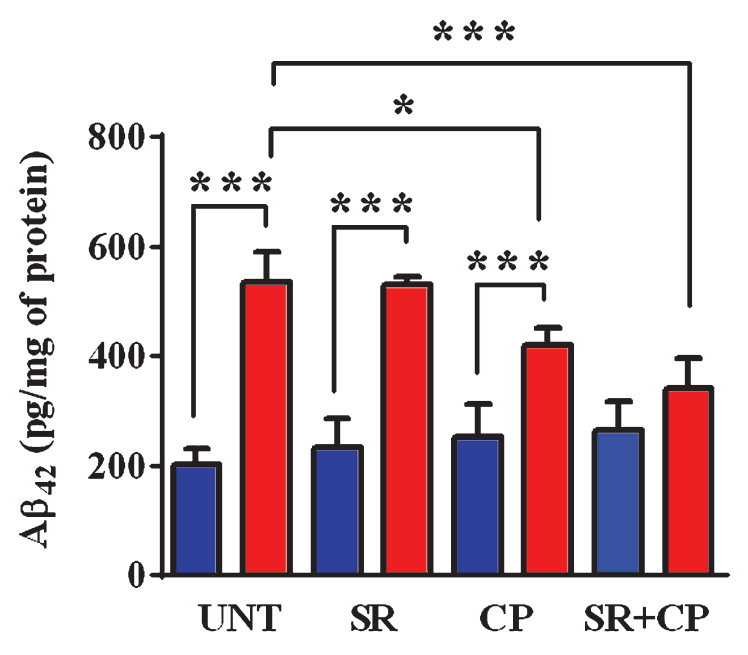

\section{PSEN1 WT $\square$ PSEN1 E280A}

Fig. 6. CP55940 reduced the levels of extracellular $A \beta_{42}$ peptide in PSEN1 E280A ChLNs by a CB ${ }_{1}$ R-independent mechanism. After 7 days of transdifferentiation, WT PSEN1 and PSEN1 E280A ChLNs were left untreated or treated with SR, CP, or SR + CP in $\mathrm{RCm}$ for 4 days. ELISA quantification of extracellular $\mathrm{A} \beta_{42}$ peptide in supernatants. Data are presented as means $\pm \mathrm{SD}$. ${ }^{*} \mathrm{p}<0.05$; ${ }^{* *} \mathrm{p}<0.01 ;{ }^{* * *} \mathrm{p}<0.001$. The histograms and figures represent 1 out of 4 independent experiments. (e.g., $\mathrm{H}_{2} \mathrm{O}_{2}$ ) [22-28] and partially diminished ROS through $\mathrm{CB}_{1} \mathrm{Rs}$ signaling. These observations may indicate that $\mathrm{CP}$ operates in a dual-way: as an antioxidant and as $\mathrm{CB}_{1}$ Rs ligand. Second, $\mathrm{CP}$ dramatically increases the $\Delta \Psi_{\mathrm{m}}$ in PSEN1 E280A ChLNs. Several data indicate that $\mathrm{CP}$ and other cannabinoids (e.g., THC, arachidonyl-2-chloroethylamide) can protect mitochondria against OS stimuli by inhibition of mitochondria permeability transition pore (mPTP) opening [37] or through activation of mitochondrial (mt) $\mathrm{CB}_{1}$ Rs $[38,39]$. Even though, $\mathrm{mtCB}_{1}$ Rs activation have been linked to an intra-mitochondrial signaling cascade involving lessening of the activity of the electron transport system, oxygen consumption, and ATP production [40], our data favor the view that inhibition of $\mathrm{mPTP}$ opening by $\mathrm{CP}$ might be responsible for neuroprotective action on mutant ChLNs [37]. Indeed, it has been shown that the $\mathrm{CB}_{2}$ agonist JWH-015 attenuated mitochondrial damage against OS stimuli by scavenging anion superoxide radical $\left(\mathrm{O}_{2}^{-{ }^{-}}\right)$and $\mathrm{H}_{2} \mathrm{O}_{2}$, maintaining $\Delta \Psi_{\mathrm{m}}$ and avoiding $\mathrm{Ca}^{2+}$-induced mitochondrial swelling [37]. Additionally, CP may indirectly protect mitochondria by blocking the interaction of $\mathrm{sA} \beta \mathrm{PP} \beta \mathrm{f}$ and mitochondrial respiratory complexes [41,42] or
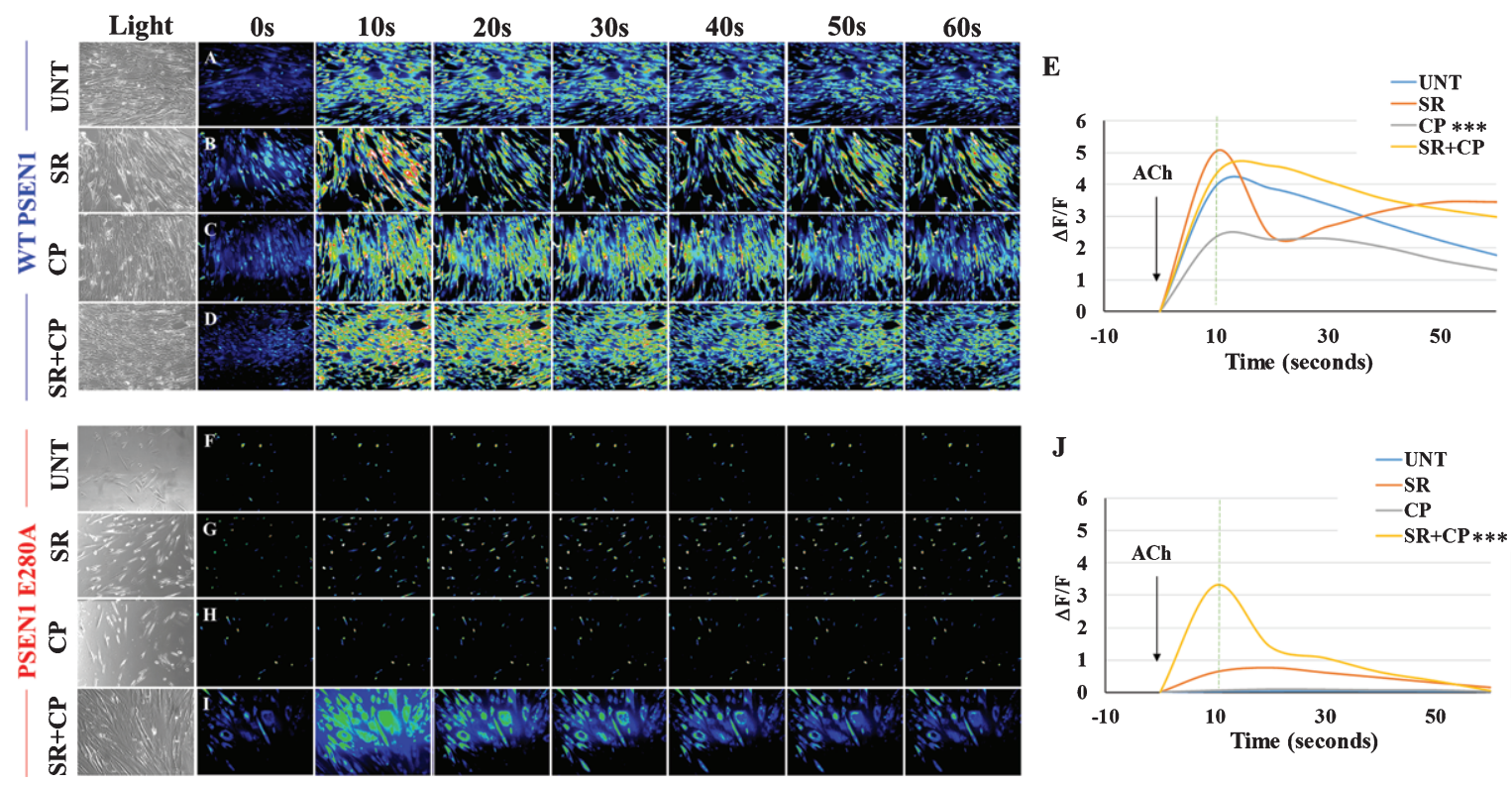

Fig. 7. CP55940 does not recover $\mathrm{Ca}^{2+}$ dysregulation in PSEN1 E280A ChLNs. After 7 days of transdifferentiation, WT PSEN1 and PSEN1 E280A ChLNs were left untreated or treated with SR, CP, or SR + CP in regular culture medium for 4 days. A-D, F-I) Time-lapse images (0, $10,20,30,40,50$, and $60 \mathrm{~s}$ ) of $\mathrm{Ca}^{2+}$ fluorescence in WT PSEN1 and PSEN1 E280A ChLNs on day 4 in response to ACh treatment. ACh was puffed into the culture at $0 \mathrm{~s}$ (arrow). Then, the $\mathrm{Ca}^{2+}$ fluorescence of the cells was monitored at the indicated times. Color contrast indicates fluorescence intensity: dark blue $<$ light blue $<$ green $<$ yellow $<$ red. E, J) Normalized mean fluorescence signal $(\Delta \mathrm{F} / \mathrm{F})$ over time from the cells indicating temporal cytoplasmic $\mathrm{Ca}^{2+}$ elevation in response to ACh treatment. Data are presented as the mean \pm SD. ${ }^{*} \mathrm{p}<0.05 ;{ }^{* *} \mathrm{p}<0.01$; ${ }^{* * *} \mathrm{p}<0.001$ compared to UNT. The histograms and figures represent 1 out of 3 independent experiments. Image magnification, $200 \times$. 


\section{(+) 6E10 antibody}
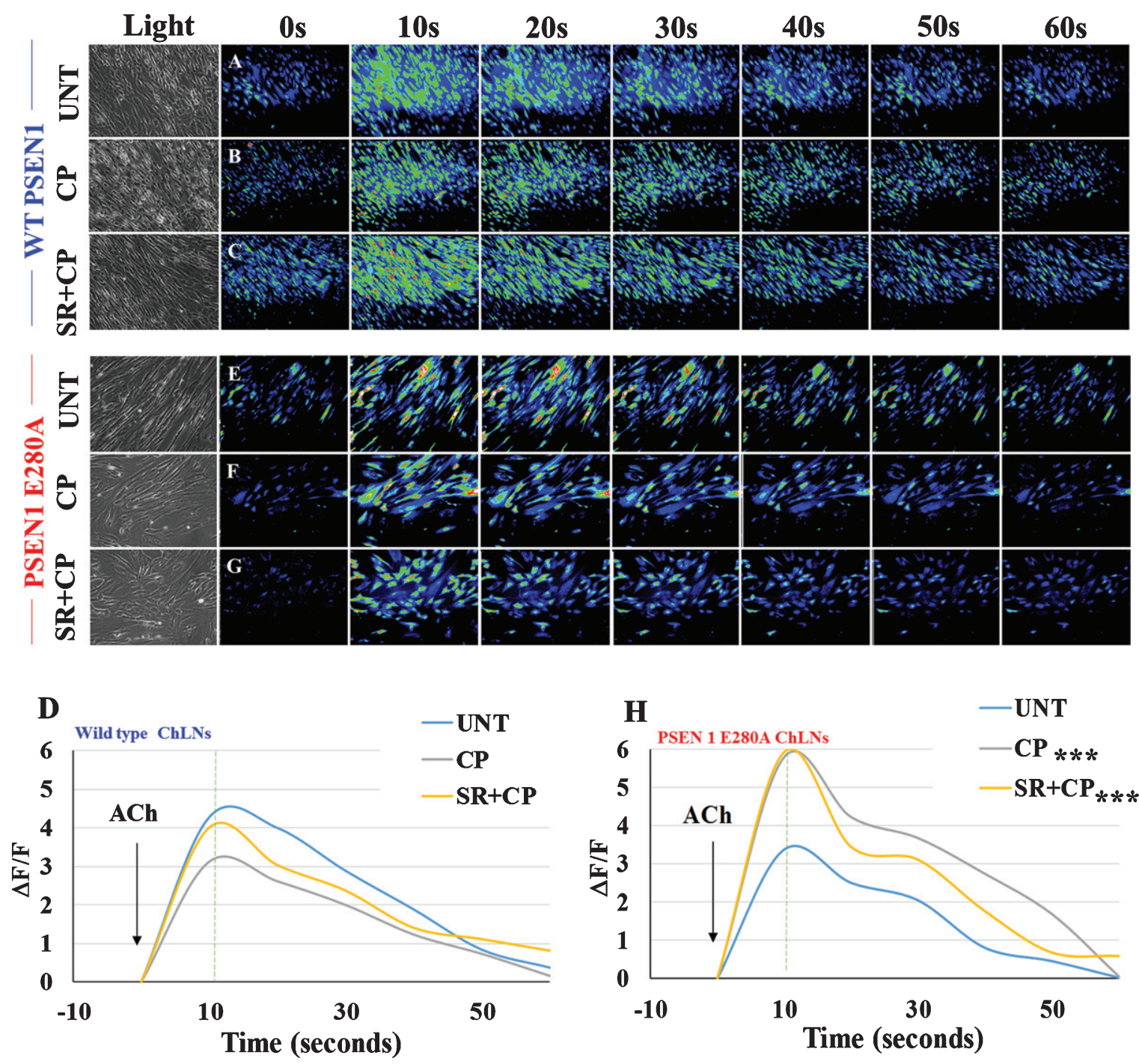

Fig. 8. CP55940 plus SR and anti-A $\beta_{42}$ antibody $6 \mathrm{E} 10$ completely recover $\mathrm{Ca}^{2+}$ influx in PSEN1 E280A ChLNs. After 7 days of transdifferentiation, WT PSEN1 and PSEN1 E280A ChLNs were incubated with 6E10 antibody as described in Materials and Methods section. Simultaneously cells were left untreated or treated with CP or SR + CP in RCm for 4 days. A-C, E-G) Time-lapse images (0, 10, 20, 30, 40, 50, and $60 \mathrm{~s}$ ) of $\mathrm{Ca}^{2+}$ fluorescence in WT PSEN1 and PSEN1 E280A ChLNs at day4 in the presence of 6E10 antibody as a response to ACh treatment. ACh was puffed into the culture at $0 \mathrm{~s}$ (arrow). Then, the $\mathrm{Ca}^{2+}$ fluorescence of the cells was monitored at the indicated times. Color contrast indicates fluorescence intensity: dark blue $<$ light blue $<$ green $<$ yellow $<$ red. D, H) Normalized mean fluorescence signal $(\Delta \mathrm{F} / \mathrm{F})$ over time from the cells indicating temporal cytoplasmic $\mathrm{Ca}^{2+}$ elevation in response to ACh treatment. Data are presented as means \pm SD. ${ }^{*} \mathrm{p}<0.05 ;{ }^{* *} \mathrm{p}<0.01 ;{ }^{* * *} \mathrm{p}<0.001$ compared to UNT. The histograms and figures represent 1 out of 3 independent experiments. Image magnification, $200 \times$.

by inhibition of mitochondria-targeted pro-apoptotic proteins (e.g., PUMA, this work). Taken together our findings suggest that CP reverses the loss of $\Delta \Psi_{\mathrm{m}}$ and mitochondria damage independently of plasma membrane $\mathrm{CB}_{1}$ receptors or $(\mathrm{mt}) \mathrm{CB}_{1} \mathrm{Rs}$. Third, it is known that cannabinoids (e.g., THC) stimulate the removal of intracellular $A \beta$ through a dependent [43] or independent $\mathrm{CB}_{1}$ Rs mechanism [22]. Here, we report for the first time that $\mathrm{CP}$ inhibits the aggregation of (i)sA $\beta P P \beta f$ in PSEN1 E280A ChLNs independently of $\mathrm{CB}_{1}$ receptor signaling. Since $A \beta_{42}$ is still detected extracellularly in mutant neurons treated with $\mathrm{CP}$, it might imply that this cannabinoid does not interfere with the A $\beta P P$ metabolism. Finally, CP significantly 
diminished oxidation of protein DJ-1, as evidence of OS. Because DJ-1Cys ${ }^{106} \mathrm{SH}$ residue is specifically sensible to $\mathrm{H}_{2} \mathrm{O}_{2}$ oxidation [44], it is likely that CP might directly interact with ROS or induces its suppression via $\mathrm{CB}_{1}$ Rs activation. Taken together our results comply with the view that early aggregation of (i)sA $\beta P P \beta f$ and generation of $\mathrm{H}_{2} \mathrm{O}_{2}$ can be blocked by the direct action of cannabinoid $\mathrm{CP}$ and by partial activation of $\mathrm{CB}_{1}$ Rs, respectively.

Recent data have shown that (i)sA $\beta P P \beta f\left(/ \mathrm{H}_{2} \mathrm{O}_{2}\right)$ induce activation of JNK/c-Jun and p53, which in turn activate PUMA and caspase-3 [16]. Interestingly, we found that $\mathrm{CP}$ blocks activation of transcription factors c-Jun, p53, PUMA, and caspase-3 independently of $\mathrm{CB}_{1} \mathrm{Rs}$ stimulation. These observations suggest that $\mathrm{CP}$ exerted a direct role in protecting PSEN1 E280A ChLNs against endogenously OSinduced cell death signaling. Since downregulation of c-Jun and p53 may reduce transcription of PUMA [45-47], CP may restrain mitochondria from leaking pro-apoptogenic proteins such as caspase-9, and ensuing activation of caspase-3. These actions avoid neuronal dismantling and increase the survival of mutant ChLNs.

Previously, it has been shown that (i)sA $\beta P P \beta f$ induces p-Tau through JNK kinase in PSEN 1 E280A ChLNs [16]. In this work, we demonstrate that CP almost completely inhibits the phosphorylation of protein tau independently of $\mathrm{CB}_{1}$ Rs. One possible explanation is that $\mathrm{CP}$ can suppress $\mathrm{H}_{2} \mathrm{O}_{2}$ generation, which serves as a messenger molecule that triggers activation of JNK [48, 49], and phosphorylation of tau [50]. It is therefore not surprising that p-Tau was untraceable in PSEN1 E280A ChLNs. However, we do not discard the possibility that $\mathrm{CP}$ blocks pTau by alternative $\mathrm{CB}_{1}$ Rs-independent mechanisms in ChLNs [51].

Mounting evidence has demonstrated that eA $\beta$ is neurotoxic before the appearance of plaques $[16,52$, 53]. Interestingly, $C P$ reduced the amounts of eA $\beta_{42}$ in a $\mathrm{CB}_{1}$ Rs-independent manner. This observation suggests that $\mathrm{CP}$ directly modulates intracellular and extracellular A $\beta P P$-derived protein fragments. However, the action of $\mathrm{CP}$ on $\mathrm{eA} \beta_{42}$ did not impact on the response of mutant ChLNs to ACh stimuli. Here, we confirm that ACh receptors (AChRs) are physiologically altered in PSEN 1 E280A ChLNs [16] most probably through $A \beta$-induced inhibition of nicotinic (n)AChRs [54, 55], which normally revealed a rapid elevation of intracellular $\mathrm{Ca}^{2+}[56-58]$ as shown in WT ChLNs. Indeed, AChRs were irresponsive to ACh stimuli, thereby nullifying the transient rise of intracellular $\mathrm{Ca}^{2+}$ in mutant ChLNs (i.e., $-99 \%$ reduction in $\left[\mathrm{Ca}^{2}{ }^{+}\right]_{\mathrm{i}}$ ) compared to wild type ChLNs. On the other hand, CP decreased $\left[\mathrm{Ca}^{2}{ }^{+}\right]_{\mathrm{i}}$ by $-68 \%$ in WT ChLNs. These observations suggest that $\mathrm{CP}$ either directly inhibited the function of AChRs [59, 60] and/ or inhibited the inflow of $\mathrm{Ca}^{2+}$ via activation of $\mathrm{CB}_{1} \mathrm{Rs}$ on calcium channels (e.g., T, Nand P/Q-type [20]). Since the response of PSEN 1 E280A ChLNs to ACh is already compromised, CP was not able to modify the influx of $\mathrm{Ca}^{2+}$ when challenged with the neurotransmitter. Interestingly, SR only or with CP increased $\left[\mathrm{Ca}^{2+}\right]_{\mathrm{i}}$ in PSEN 1 E280A ChLNs compared to untreated mutant ChLNs. This positive improvement of $\mathrm{Ca}^{2+}$ inflow was comparable to WT ChLNs (see CP+SR effect on neurons). These observations can be explained by the fact that SR can either stimulate $\mathrm{Ca}^{2+}$ influx through $\mathrm{Ca}^{2+}$ channels (e.g., $\mathrm{Ca}_{\mathrm{v}} 2: \mathrm{N}-, \mathrm{P} / \mathrm{Q}$ channels [61]) or block the negative interaction of $\mathrm{CP}$ with $\mathrm{nAChRs}$ in WT ChLNs when exposed to ACh (this work). Our findings suggest that $\mathrm{CB}_{1}$ Rs are marginally active in PSEN 1 E280A ChLNs. Interestingly; anti-A $\beta_{42}$ antibody completely recovered transient intracellular $\mathrm{Ca}^{2+}$ signal in mutant ChLNs. The $\mathrm{Ca}^{2+}$ signal was further increased when neurons were co-cultured with $\mathrm{CP}$ only or SR plus $\mathrm{CP}$. These last observations reinforce the view that $A \beta_{42}$ and SR interfere with $C P$ and AChRs. Similar to PSEN 1 E280A ChLNs, antibody anti- $\mathrm{A} \beta_{42}$ increased transient intracellular $\mathrm{Ca}^{2+}$ signals in WT ChLNs. These observations imply that eA $\beta_{42}$ secreted in low amounts by WT ChLNs or abnormally secreted in high amounts by mutant ChLNs is an AChRs regulator in ChLNs. Taken together these observations suggest that a combination of $\mathrm{CP}$ with anti-A $\beta_{42}$ would be therapeutically beneficial to FAD patients.

\section{Conclusion}

In an attempt to modify the neuropathological expression of ChLNs bearing the mutation PSEN1 E280A (e.g., intracellular aggregation of sA $\beta P P \beta f$, tau phosphorylation, OS, apoptosis, and $\mathrm{Ca}^{2+}$ influx dysfunction) (Fig. 9A), we found that cannabinoid CP is a multi-target molecule that promotes the recovery FAD cholinergic neurons by increasing $\Delta \Psi_{\mathrm{m}}$, impedes phosphorylation of protein tau, and blocks OS-induced apoptosis signaling (Fig. 9B). However, $\mathrm{CP}$ was unable to modify the neuronal functionality as evidenced by an inability of ACh to increase $\mathrm{Ca}^{2+}$ influx in PSEN1 E280A ChLNs. Since the nature of 
the neuronal cholinergic dysfunctionality stems from the blocking of $n A C h R s$ by $A \beta_{42}[54,55]$, drugs that interfere with the interaction of $A \beta$ and the AChRs might ameliorate the ligand-gated ion $\mathrm{Ca}^{2+}$ channel interactions (e.g., [62]). In this respect, we show that anti-A $\beta_{42}$ antibody $6 \mathrm{E} 10$ plus $\mathrm{CP}$ or anti-A $\beta_{42}$ and $\mathrm{SR}+\mathrm{CP}$ change mutant ChLNs response to $\mathrm{ACh}$ by increasing $\mathrm{Ca}^{2+}$ influx to similar $\left[\mathrm{Ca}^{2+}\right]_{\mathrm{i}}$ in WT ChLNs (Fig. 9C, D). It is therefore proposed that combinations of cannabinoids, anti- $\mathrm{A} \beta_{42}$ antibodies (e.g., crenezumab $[63,64]$ ), and $\mathrm{CB}_{1}$ inverse agonists might be a promising multi-target drugs for therapy [65] in the early treatment of FAD PSEN 1 E280A ChLNs neurodegeneration.

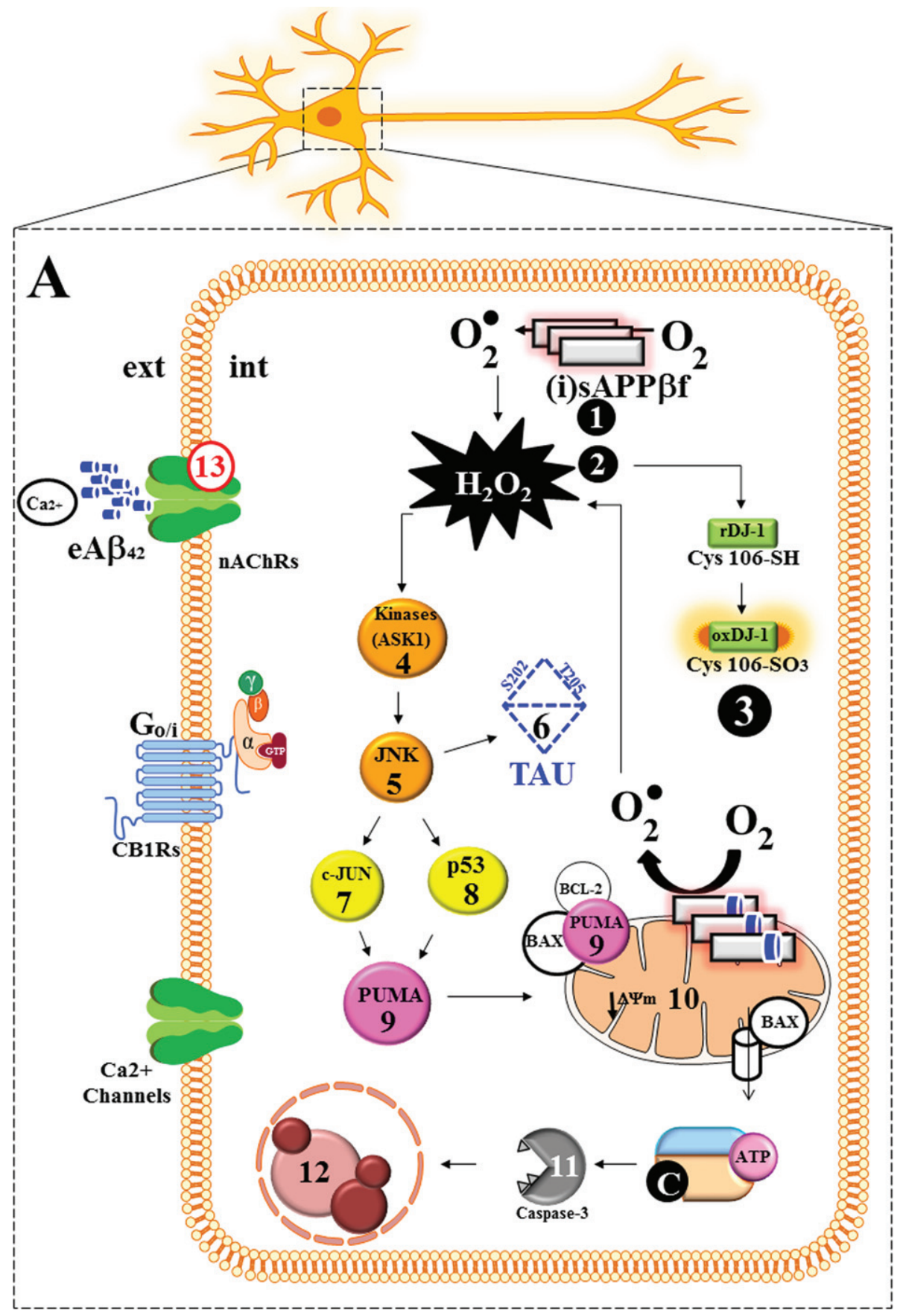

Fig. 9. (Continued) 


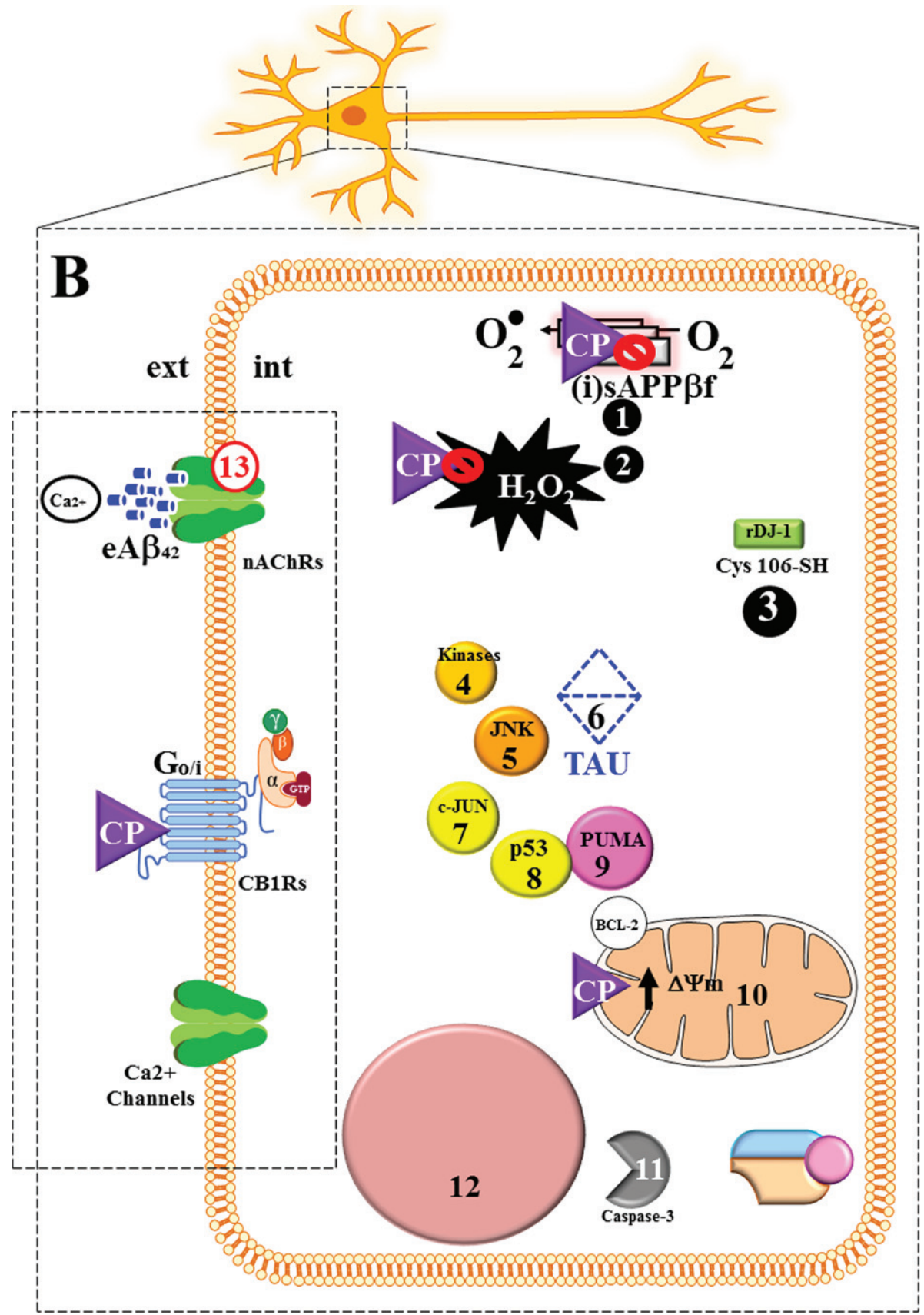

Fig. 9. (Continued) 


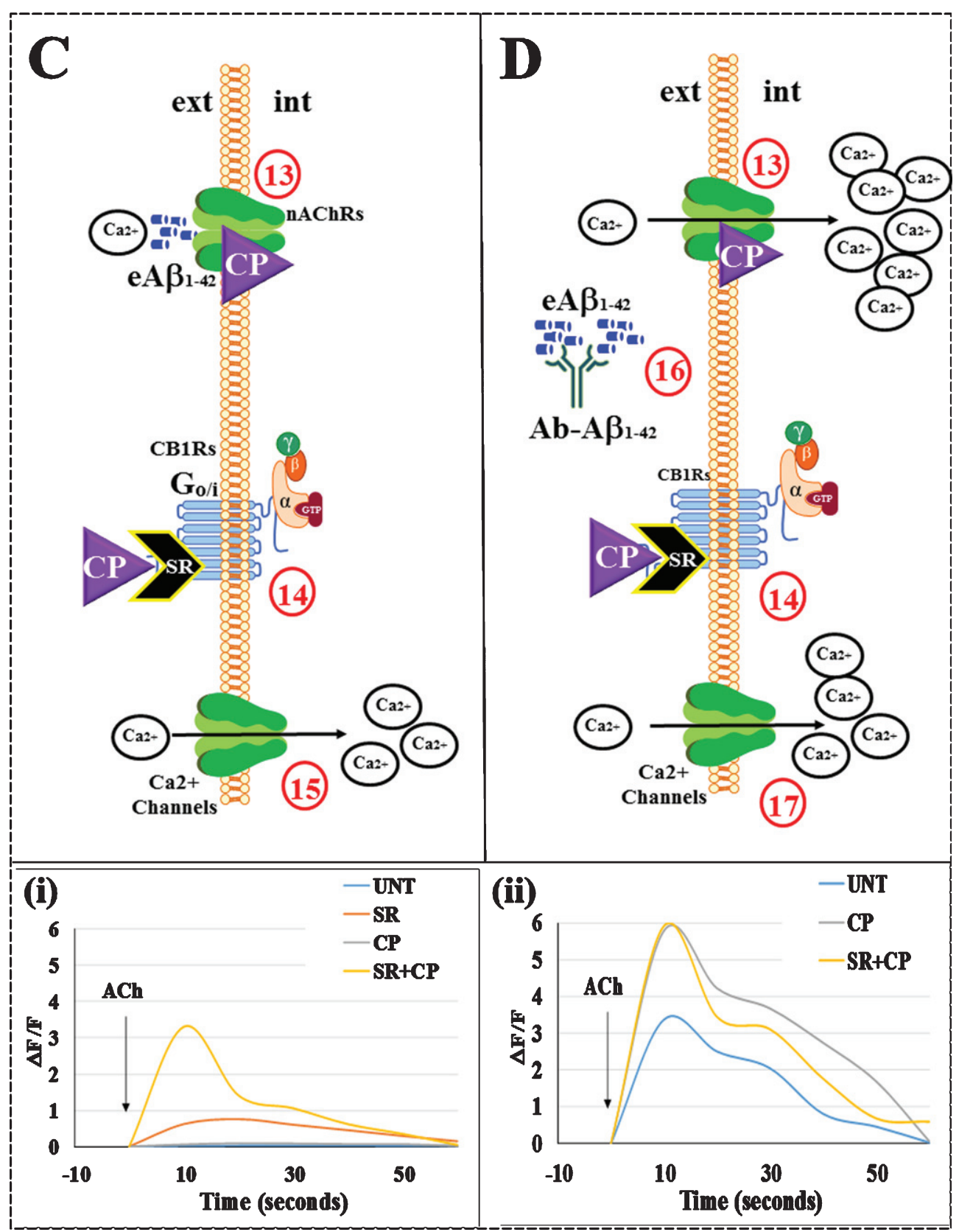

Fig. 9. Schematic representation of the protective effect of CP55940 on PSEN 1 E280A ChLNs. A) Intracellularly accumulation of sA $\beta P P \beta f$ (step 1) generates $\mathrm{H}_{2} \mathrm{O}_{2}$ (s2), which in turn oxidized the OS sensor protein DJ-1 at Cys- ${ }^{106}-\mathrm{SH}_{\text {residue into }} \mathrm{DJ}-1 \mathrm{Cys}{ }^{106}-\mathrm{SO}_{3}$ (s3) and activates a domino-like pro-death signaling mechanism by triggering kinases (s4, e.g., ASK1) and JNK kinase (s5). This last kinase phosphorylates protein tau (s6) and activates the transcription factors c-Jun (s7) and p53 (s8). Both transcription factors transcribe the BH-3-only protein PUMA (s9), which together with other pro-apoptosis proteins (e.g., BAX), it induces depolarization of mitochondria, opening of the mitochondrial transition pore, and loss of mitochondrial membrane potential $\left(\Delta \Psi_{\mathrm{m}}, \mathrm{s} 10\right)$. Damage of mitochondria potential provokes the release of pro-apoptogenic protein cytochrome $\mathrm{C}$, ensuing activation of caspase-3 (s11). In turn, this protease activates the endonuclease DFF40 by cleaving the nuclease's inhibitor DFF45. Finally, DFF40 causes the nuclear chromatin fragmentation, typical of apoptosis (s12). Additionally, ChLNs do not respond to ACh stimuli, i.e., intracellular transient $\mathrm{Ca}^{2+}$ increase is missing due to extracellular interaction between $A \beta_{42}\left(\mathrm{eA} \beta_{42}\right)$ and nicotinic (n)ACh receptors (s13). The sA $\beta P P \beta f$-induced process (s1-s13) leads ChL neurons to structural alterations (e.g., aggregation/ hyperphosphorylation of protein tau), cell death (apoptosis) and intracellular Ca $\mathrm{Ca}^{2+}$ dysfunction. B) Upon exposure to CP55940 (CP), ChLNs show normal features such as no oxidized protein DJ-1 (s3), unaltered $\Delta \Psi_{\mathrm{m}}(\mathrm{s} 10)$, and intact nuclei 
morphology (s12). Moreover, CP inhibits aggregation of $\mathrm{sA} \beta P P \beta f\left(\mathrm{~s} 1\right.$ ), and blocks generation of $\mathrm{H}_{2} \mathrm{O}_{2}$ (s2) most probably by quenching anion superoxide radicals $\left(\mathrm{O}_{2}{ }^{-}\right.$). As a consequence, no further activation of kinases ( $\left.\mathrm{s} 4, \mathrm{~s} 5\right)$, phosphorylation of protein tau (s6), and c-Jun (s7), and activation of p53 (s8), PUMA (s9), and caspase-3 (s11) occurs in PSEN1 E280A ChLNs just leaving mitochondria and nuclei unchanged from sA $\beta P P \beta f$-induced damage. C) Since $n A C h R s$ are blocked by eA $\beta_{42}$ (s13), CP was unable to modify the response of mutant ChLNs to $\mathrm{ACh}$ (inset graph i). Interestingly, the $\mathrm{CB}_{1}$ and $\mathrm{CB}_{2}$ receptor inverse agonists SR141716 plus SR144528 (=SR) only or in the presence of $\mathrm{CP}$ induce a significant increase in intracellular $\mathrm{Ca}^{2+}(\mathrm{s} 14)$ most probably through activation of $\mathrm{Ca}^{2+}$ channels (s15 and inset graph i). D) When mutant ChLNs were exposed to CP, SR, and anti-A $\beta_{42}$ antibody $6 \mathrm{E} 10$ (s16), the mixture induced a dramatic increase in the transient intracellular $\mathrm{Ca}^{2+}$ flow (s13, s17 and inset graph ii).

\section{ACKNOWLEDGMENTS}

This study was funded by MinCiencias grant \# 1115-844-67062, contract \#830-2019 to CV-P, MJDel-Rio, and MM-P. VS-M is a doctoral student of the Basic Biomedical Sciences Academic Corporation program at the Universidad de Antioquia (UdeA) funded by the "2019 Bicentennial Doctoral Excellence Scholarship", MinCiencias-Colombia.

Authors' disclosures available online (https:// www.j-alz.com/manuscript-disclosures/20-1045r2).

\section{REFERENCES}

[1] Long JM, Holtzman DM (2019) Alzheimer disease: An update on pathobiology and treatment strategies. Cell 179, 312-339.

[2] Hampel H, Mesulam MM, Cuello AC, Farlow MR, Giacobini E, Grossberg GT, Khachaturian AS, Vergallo A, Cavedo E, Snyder PJ, Khachaturian ZS (2018) The cholinergic system in the pathophysiology and treatment of Alzheimer's disease. Brain 141, 1917-1933.

[3] DeTure MA, Dickson DW (2019) The neuropathological diagnosis of Alzheimer's disease. Mol Neurodegener 14, 32 .

[4] Yuksel M, Tacal O (2019) Trafficking and proteolytic processing of amyloid precursor protein and secretases in Alzheimer's disease development: An up-to-date review. Eur J Pharmacol 856, 172415.

[5] Kabir MT, Uddin MS, Setu JR, Ashraf GM, Bin-Jumah MN, Abdel-Daim MM (2020) Exploring the role of PSEN mutations in the pathogenesis of Alzheimer's disease. Neurotox Res 38, 833-849.

[6] Sun L, Zhou R, Yang G, Shi Y (2017) Analysis of 138 pathogenic mutations in presenilin-1 on the in vitro production of Abeta42 and Abeta40 peptides by gamma-secretase. Proc Natl Acad Sci U S A 114, E476-E485.

[7] Lopera F, Ardilla A, Martinez A, Madrigal L, Arango-Viana JC, Lemere CA, Arango-Lasprilla JC, Hincapie L, ArcosBurgos M, Ossa JE, Behrens IM, Norton J, Lendon C, Goate AM, Ruiz-Linares A, Rosselli M, Kosik KS (1997) Clinical features of early-onset Alzheimer disease in a large kindred with an E280A presenilin-1 mutation. JAMA 277, 793-799.

[8] Sepulveda-Falla D, Glatzel M, Lopera F (2012) Phenotypic profile of early-onset familial Alzheimer's disease caused by presenilin-1 E280A mutation. J Alzheimers Dis 32, 1-12.

[9] Fuller JT, Cronin-Golomb A, Gatchel JR, Norton DJ, Guzman-Velez E, Jacobs HIL, Hanseeuw B, PardillaDelgado E, Artola A, Baena A, Bocanegra Y, Kosik KS, Chen K, Tariot PN, Johnson K, Sperling RA, Reiman EM,
Lopera F, Quiroz YT (2019) Biological and cognitive markers of presenilin1 E280A autosomal dominant Alzheimer's disease: A comprehensive review of the Colombian kindred. J Prev Alzheimers Dis 6, 112-120.

[10] Lalli MA, Cox HC, Arcila ML, Cadavid L, Moreno S, Garcia G, Madrigal L, Reiman EM, Arcos-Burgos M, Bedoya G, Brunkow ME, Glusman G, Roach JC, Hood L, Kosik KS, Lopera F (2014) Origin of the PSEN1 E280A mutation causing early-onset Alzheimer's disease. Alzheimers Dement 10, S277-S283.e210.

[11] Zhou R, Yang G, Shi Y (2017) Dominant negative effect of the loss-of-function gamma-secretase mutants on the wild-type enzyme through heterooligomerization. Proc Natl Acad Sci U S A 114, 12731-12736.

[12] Lemere CA, Lopera F, Kosik KS, Lendon CL, Ossa J, Saido TC, Yamaguchi H, Ruiz A, Martinez A, Madrigal L, Hincapie L, Arango JC, Anthony DC, Koo EH, Goate AM, Selkoe DJ (1996) The E280A presenilin 1 Alzheimer mutation produces increased A beta 42 deposition and severe cerebellar pathology. Nat Med 2, 1146-1150.

[13] Velez-Pardo C, Arellano JI, Cardona-Gomez P, Jimenez Del Rio M, Lopera F, De Felipe J (2004) CA1 hippocampal neuronal loss in familial Alzheimer's disease presenilin1 E280A mutation is related to epilepsy. Epilepsia 45, 751-756.

[14] Fleisher AS, Chen K, Quiroz YT, Jakimovich LJ, Gomez MG, Langois CM, Langbaum JB, Ayutyanont N, Roontiva A, Thiyyagura P, Lee W, Mo H, Lopez L, Moreno S, AcostaBaena N, Giraldo M, Garcia G, Reiman RA, Huentelman MJ, Kosik KS, Tariot PN, Lopera F, Reiman EM (2012) Florbetapir PET analysis of amyloid- $\beta$ deposition in the presenilin 1 E280A autosomal dominant Alzheimer's disease kindred: A cross-sectional study. Lancet Neurol 11, 1057-1065.

[15] Quiroz YT, Sperling RA, Norton DJ, Baena A, ArboledaVelasquez JF, Cosio D, Schultz A, Lapoint M, GuzmanVelez E, Miller JB, Kim LA, Chen K, Tariot PN, Lopera F, Reiman EM, Johnson KA (2018) Association between amyloid and tau accumulation in young adults with autosomal dominant Alzheimer disease. JAMA Neurol 75, 548-556.

[16] Soto-Mercado V, Mendivil-Perez M, Velez-Pardo C, Lopera F, Jimenez-Del-Rio M (2020) Cholinergic-like neurons carrying PSEN1 E280A mutation from familial Alzheimer's disease reveal intraneuronal sAPP $\beta$ fragments accumulation, hyperphosphorylation of tau, oxidative stress, apoptosis and $\mathrm{Ca} 2+$ dysregulation: Therapeutic implications. PLoS One 15, e0221669.

[17] Bonini SA, Premoli M, Tambaro S, Kumar A, Maccarinelli G, Memo M, Mastinu A (2018) Cannabis sativa: A comprehensive ethnopharmacological review of a medicinal plant with a long history. J Ethnopharmacol 227, 300-315.

[18] Cassano T, Villani R, Pace L, Carbone A, Bukke VN, Orkisz S, Avolio C, Serviddio G (2020) From Cannabis sativa to cannabidiol: Promising therapeutic candidate for the 
treatment of neurodegenerative diseases. Front Pharmacol 11, 124.

[19] ElSohly MA, Radwan MM, Gul W, Chandra S, Galal A (2017) Phytochemistry of Cannabis sativa L. Prog Chem Org Nat Prod 103, 1-36.

[20] Marcu J, Schechter J (2016) Molecular pharmacology of CB1 and CB2 cannabinoid receptors. In Neuropathology of Drug Addictions and Substance Misuse, Preedy V, ed. Academic Press, pp. 713-721.

[21] Shahbazi F, Grandi V, Banerjee A, Trant JF (2020) Cannabinoids and cannabinoid receptors: The story so far. iScience 23, 101301.

[22] Schubert D, Kepchia D, Liang Z, Dargusch R, Goldberg J, Maher P (2019) Efficacy of cannabinoids in a pre-clinical drug-screening platform for Alzheimer's disease. Mol Neurobiol 56, 7719-7730.

[23] Hampson AJ, Grimaldi M, Axelrod J, Wink D (1998) Cannabidiol and (-)Delta9-tetrahydrocannabinol are neuroprotective antioxidants. Proc Natl Acad Sci U S A 95, 8268-8273.

[24] Chen Y, Buck J (2000) Cannabinoids protect cells from oxidative cell death: A receptor-independent mechanism. $J$ Pharmacol Exp Ther 293, 807-812.

[25] Marsicano G, Moosmann B, Hermann H, Lutz B, Behl C (2002) Neuroprotective properties of cannabinoids against oxidative stress: Role of the cannabinoid receptor CB1. $J$ Neurochem 80, 448-456.

[26] Jimenez-Del-Rio M, Daza-Restrepo A, Velez-Pardo C (2008) The cannabinoid CP55,940 prolongs survival and improves locomotor activity in Drosophila melanogaster against paraquat: Implications in Parkinson's disease. Neurosci Res 61, 404-411.

[27] Velez-Pardo C, Del Rio MJ (2006) Avoidance of Abeta[(25$35)] /(\mathrm{H}(2) \mathrm{O}(2))$-induced apoptosis in lymphocytes by the cannabinoid agonists CP55,940 and JWH-015 via receptorindependent and PI3K-dependent mechanisms: Role of NFkappaB and p53. Med Chem 2, 471-479.

[28] Harvey BS, Ohlsson KS, Mååg JL, Musgrave IF, Smid SD (2012) Contrasting protective effects of cannabinoids against oxidative stress and amyloid- $\beta$ evoked neurotoxicity in vitro. Neurotoxicology 33, 138-146.

[29] Pertwee R, Cannabinoid Receptor Ligands, https://www. tocris.com/literature/scientific-reviews/cannabinoidreceptor-ligands, Accessed Aug. 2020.

[30] Mendivil-Perez M, Velez-Pardo C, Jimenez-Del-Rio M (2019) Direct transdifferentiation of human Wharton's jelly mesenchymal stromal cells into cholinergic-like neurons. $J$ Neurosci Methods 312, 126-138.

[31] Gulisano W, Melone M, Ripoli C, Tropea MR, Li Puma DD, Giunta S, Cocco S, Marcotulli D, Origlia N, Palmeri A, Arancio O, Conti F, Grassi C, Puzzo D (2019) Neuromodulatory action of picomolar extracellular $\mathrm{A} \beta 42$ oligomers on presynaptic and postsynaptic mechanisms underlying synaptic function and memory. $J$ Neurosci 39, 5986-6000.

[32] Armijo E, Gonzalez C, Shahnawaz M, Flores A, Davis B, Soto C (2017) Increased susceptibility to Abeta toxicity in neuronal cultures derived from familial Alzheimer's disease (PSEN1-A246E) induced pluripotent stem cells. Neurosci Lett 639, 74-81.

[33] Pap P, Koszeghy A, Szucs G, Rusznak Z (2009) Cytoplasmic $\mathrm{Ca}(2+)$ concentration changes evoked by cholinergic stimulation in primary astrocyte cultures prepared from the rat cochlear nucleus. Hear Res 255, 73-83.

[34] Sekiguchi-Tonosaki M, Obata M, Haruki A, Himi T, Kosaka J (2009) Acetylcholine induces Ca2+signaling in chicken retinal pigmented epithelial cells during dedifferentiation. Am J Physiol Cell Physiol 296, C1195-1206.

[35] Lazic SE, Clarke-Williams CJ, Munafo MR (2018) What exactly is ' $\mathrm{N}$ ' in cell culture and animal experiments? PLoS Biol 16, e2005282.

[36] Nyíri G, Szabadits E, Cserép C, Mackie K, Shigemoto R, Freund TF (2005) GABAB and CB1 cannabinoid receptor expression identifies two types of septal cholinergic neurons. Eur J Neurosci 21, 3034-3042.

[37] Velez-Pardo C, Jimenez-Del-Rio M, Lores-Arnaiz S, Bustamante J (2010) Protective effects of the synthetic cannabinoids CP55,940 and JWH-015 on rat brain mitochondria upon paraquat exposure. Neurochem Res 35 , 1323-1332.

[38] Benard G, Massa F, Puente N, Lourenco J, Bellocchio L, Soria-Gomez E, Matias I, Delamarre A, Metna-Laurent M, Cannich A, Hebert-Chatelain E, Mulle C, Ortega-Gutierrez S, Martin-Fontecha M, Klugmann M, Guggenhuber S, Lutz B, Gertsch J, Chaouloff F, Lopez-Rodriguez ML, Grandes P, Rossignol R, Marsicano G (2012) Mitochondrial CB(1) receptors regulate neuronal energy metabolism. $\mathrm{Nat} \mathrm{Neu-}$ rosci 15, 558-564.

[39] Ma L, Niu W, Yang S, Tian J, Luan H, Cao M, Xi W, Tu W, Jia J, Lv J (2018) Inhibition of mitochondrial permeability transition pore opening contributes to cannabinoid type 1 receptor agonist ACEA-induced neuroprotection. Neuropharmacology 135, 211-222.

[40] Melser S, Pagano Zottola AC, Serrat R, Puente N, Grandes P, Marsicano G, Hebert-Chatelain E (2017) Functional analysis of mitochondrial CB1 cannabinoid receptors (mtCB1) in the brain. Methods Enzymol 593, 143-174.

[41] Devi L, Prabhu BM, Galati DF, Avadhani NG, Anandatheerthavarada HK (2006) Accumulation of amyloid precursor protein in the mitochondrial import channels of human Alzheimer's disease brain is associated with mitochondrial dysfunction. J Neurosci 26, 9057-9068.

[42] Anandatheerthavarada HK, Biswas G, Robin MA, Avadhani NG (2003) Mitochondrial targeting and a novel transmembrane arrest of Alzheimer's amyloid precursor protein impairs mitochondrial function in neuronal cells. J Cell Biol 161, 41-54.

[43] Currais A, Quehenberger O, M Armando A, Daugherty D, Maher P, Schubert D (2016) Amyloid proteotoxicity initiates an inflammatory response blocked by cannabinoids. NPJ Aging Mech Dis 2, 16012.

[44] Kinumi T, Kimata J, Taira T, Ariga H, Niki E (2004) Cysteine-106 of DJ-1 is the most sensitive cysteine residue to hydrogen peroxide-mediated oxidation in vivo in human umbilical vein endothelial cells. Biochem Biophys Res Commun 317, 722-728.

[45] Nakano K, Vousden KH (2001) PUMA, a novel proapoptotic gene, is induced by p53. Mol Cell 7, 683-694.

[46] Yu J, Zhang L, Hwang PM, Kinzler KW, Vogelstein B (2001) PUMA induces the rapid apoptosis of colorectal cancer cells. Mol Cell 7, 673-682.

[47] Lu H, Hou G, Zhang Y, Dai Y, Zhao H (2014) c-Jun transactivates Puma gene expression to promote osteoarthritis. Mol Med Rep 9, 1606-1612.

[48] Saitoh M, Nishitoh H, Fujii M, Takeda K, Tobiume K, Sawada Y, Kawabata M, Miyazono K, Ichijo H (1998) Mammalian thioredoxin is a direct inhibitor of apoptosis signal-regulating kinase (ASK) 1. EMBO J 17, 2596-2606.

[49] Nishitoh H, Saitoh M, Mochida Y, Takeda K, Nakano H, Rothe M, Miyazono K, Ichijo H (1998) ASK1 is essential for JNK/SAPK activation by TRAF2. Mol Cell 2, 389-395. 
[50] Yoshida H, Hastie CJ, McLauchlan H, Cohen P, Goedert M (2004) Phosphorylation of microtubule-associated protein tau by isoforms of c-Jun N-terminal kinase (JNK). $J$ Neurochem 90, 352-358.

[51] Esposito G, De Filippis D, Carnuccio R, Izzo AA, Iuvone T (2006) The marijuana component cannabidiol inhibits betaamyloid-induced tau protein hyperphosphorylation through Wnt/beta-catenin pathway rescue in PC12 cells. $J$ Mol Med (Berl) 84, 253-258.

[52] Lei M, Xu H, Li Z, Wang Z, O’Malley TT, Zhang D, Walsh DM, Xu P, Selkoe DJ, Li S (2016) Soluble A $\beta$ oligomers impair hippocampal LTP by disrupting glutamatergic/GABAergic balance. Neurobiol Dis 85, 111-121.

[53] Cline EN, Bicca MA, Viola KL, Klein WL (2018) The amyloid-beta oligomer hypothesis: Beginning of the third decade. J Alzheimers Dis 64, S567-S610.

[54] Liu Q, Kawai H, Berg DK (2001) beta-Amyloid peptide blocks the response of alpha 7-containing nicotinic receptors on hippocampal neurons. Proc Natl Acad Sci U S A 98, 4734-4739.

[55] Pettit DL, Shao Z, Yakel JL (2001) beta-Amyloid(1-42) peptide directly modulates nicotinic receptors in the rat hippocampal slice. J Neurosci 21, RC120.

[56] Szabo GG, Lenkey N, Holderith N, Andrasi T, Nusser Z, Hajos N (2014) Presynaptic calcium channel inhibition underlies $\mathrm{CB}(1)$ cannabinoid receptor-mediated suppression of GABA release. J Neurosci 34, 7958-7963.

[57] Shen JX, Yakel JL (2009) Nicotinic acetylcholine receptormediated calcium signaling in the nervous system. Acta Pharmacol Sin 30, 673-680.

[58] Uteshev VV (2012) $\alpha 7$ nicotinic ACh receptors as a ligandgated source of $\mathrm{Ca}(2+)$ ions: The search for a $\mathrm{Ca}(2+)$ optimum. Adv Exp Med Biol 740, 603-638.

[59] Oz M, Ravindran A, Diaz-Ruiz O, Zhang L, Morales M (2003) The endogenous cannabinoid anandamide inhibits alpha7 nicotinic acetylcholine receptor-mediated responses in Xenopus oocytes. J Pharmacol Exp Ther 306, 1003-1010.
[60] Butt C, Alptekin A, Shippenberg T, Oz M (2008) Endogenous cannabinoid anandamide inhibits nicotinic acetylcholine receptor function in mouse thalamic synaptosomes. J Neurochem 105, 1235-1243.

[61] Twitchell W, Brown S, Mackie K (1997) Cannabinoids inhibit N- and P/Q-type calcium channels in cultured rat hippocampal neurons. J Neurophysiol 78, 43-50.

[62] Wang HY, Stucky A, Liu J, Shen C, Trocme-Thibierge C, Morain P (2009) Dissociating beta-amyloid from alpha 7 nicotinic acetylcholine receptor by a novel therapeutic agent, S 24795, normalizes alpha 7 nicotinic acetylcholine and NMDA receptor function in Alzheimer's disease brain. J Neurosci 29, 10961-10973.

[63] Tariot PN, Lopera F, Langbaum JB, Thomas RG, Hendrix S, Schneider LS, Rios-Romenets S, Giraldo M, Acosta N, Tobon C, Ramos C, Espinosa A, Cho W, Ward M, Clayton D, Friesenhahn M, Mackey H, Honigberg L, Sanabria Bohorquez S, Chen K, Walsh T, Langlois C, Reiman EM (2018) The Alzheimer's Prevention Initiative Autosomal-Dominant Alzheimer's Disease Trial: A study of crenezumab versus placebo in preclinical PSEN1 E280A mutation carriers to evaluate efficacy and safety in the treatment of autosomal-dominant Alzheimer's disease, including a placebo-treated noncarrier cohort. Alzheimers Dement (N Y) 4, 150-160.

[64] Meilandt WJ, Maloney JA, Imperio J, Lalehzadeh G, Earr T, Crowell S, Bainbridge TW, Lu Y, Ernst JA, Fuji RN, Atwal JK (2019) Characterization of the selective in vitro and in vivo binding properties of crenezumab to oligomeric $\mathrm{A} \beta$. Alzheimers Res Ther 11, 97.

[65] Benek O, Korabecny J, Soukup O (2020) A perspective on multi-target drugs for Alzheimer's disease. Trends Pharmacol Sci 41, 434-445. 